\title{
EC-LEDS
}

\section{Advancing Development and Greenhouse Gas Reductions in Vietnam's Wind Sector}

June 19, 2014

Daniel Bilello, Jessica Katz, Sean Esterly

National Renewable Energy Laboratory

Matthew Ogonowski

U.S. Agency for International Development 


\section{ACKNOWLEDGMENTS}

The authors would like to thank the USAID Mission team in Hanoi, Vietnam for their input and guidance on this report. Through hosting an initial workshop in early 2013 with the Government of Vietnam, a number of important insights on how to effectively support emission mitigation while advancing economic and social development were explored in depth and further expanded upon here. In addition, our Vietnamese colleagues with ENTEC including Nguyen Thi Hai Ngoc provided very helpful input drawing upon their local knowledge of the emerging wind sector in the country. Mark Jacobson and Suzanne Tegen at NREL provided very useful and in depth feedback based on their technical expertise and experience in the wind sector in their respective roles as a project developer and market analyst. Technical elements of the paper were further improved based on feedback from Allen Eisendrath and Stephanie Bogle at USAID in Washington, DC. A final thanks goes to Melissa Butheau at NREL for her review and editorial support. 


\begin{tabular}{|c|c|}
\hline \multicolumn{2}{|c|}{ LIST OF ACRONYMS AND ABBREVIATIONS } \\
\hline ASEAN & Association of Southeast Asian Nations \\
\hline EC-LEDS & Enhancing Capacity for Low Emission Development Strategies \\
\hline EE & energy efficiency \\
\hline FIT & feed-in tariff \\
\hline GHG & greenhouse gas \\
\hline GIS & geographical information system \\
\hline $\mathrm{GIZ}$ & Deutsche Gesellschaft für Internationale Zusammenarbeit \\
\hline GST & geospatial toolkit \\
\hline GW & gigawatt \\
\hline GWh & gigawatt-hour \\
\hline $\mathrm{kWh}$ & kilowatt-hour \\
\hline $\mathrm{km}$ & kilometer \\
\hline $\mathrm{km}^{2}$ & square kilometer \\
\hline LCOE & levelized cost of energy \\
\hline LEDS & low emission development strategies \\
\hline MOIT & Ministry of Industry and Trade \\
\hline $\mathrm{m}$ & meter \\
\hline $\mathrm{m} / \mathrm{s}$ & meter per second \\
\hline MW & megawatt \\
\hline O\&M & operation and maintenance \\
\hline PPA & power purchase agreement \\
\hline PTC & production tax credit \\
\hline PV & photovoltaics \\
\hline RE & renewable energy \\
\hline
\end{tabular}


REC renewable energy certificate

RPS renewable portfolio standard

T\&D transmission and distribution

UNEP United Nations Environment Programme 


\section{EXECUTIVE SUMMARY}

Clean energy development is a key component of Vietnam's Green Growth Strategy, which establishes a target to reduce greenhouse gas (GHG) emissions from domestic energy activities by 20-30 percent by 2030 relative to a business-as-usual scenario. Vietnam has significant wind energy resources, which, if developed, could help the country reach this target (and achieve sustained GHG reductions over the long term) while providing ancillary economic, social, and environmental benefits. Given Vietnam's ambitious clean energy goals and the relatively nascent state of wind energy development in the country, this paper seeks to fulfill two primary objectives:

- To distill timely and useful information to provincial-level planners, analysts, and project developers as they evaluate opportunities to develop local wind resources; and,

- To provide insights to policymakers on how coordinated efforts may help advance large-scale wind development, deliver near-term GHG emission reductions, and promote national objectives in the context of a low emission development framework.

Vietnam's theoretical wind energy potential exceeds 1,000,000 gigawatt-hours per year, which well surpasses current national electricity demand. Though less than 100 megawatts of wind capacity have been installed in Vietnam as of 2014, national and provincial policies such as the Green Growth Strategy and the National Power Development Plan articulate a vision to harness domestic wind resources (along with other renewable energy resources) to contribute an increasingly significant proportion of national energy supply over the coming decades. To bring this vision to fruition, national and local decision makers have the opportunity to develop new models for integrated planning that lay the foundation for large-scale, cost-effective wind development in a manner that advances national and local development objectives.

Integrated planning harmonizes goals not only across the energy and other economic sectors, but also across the local and national policymaking levels. This paper provides insights on approaches to coordinated policy design that advances low emission development by broadening stakeholder engagement, leveraging resources across multiple organizations and efforts, creating new market and workforce development prospects, and attracting international finance and coordination. It also details how conscientious planning for wind deployment can support specific environmental and socio-economic objectives, including water and land management, local environmental quality, energy access and security, poverty reduction, disaster risk management, and agricultural productivity.

Integrated planning at the national and sub-national levels also plays an important role in reducing risk and attracting finance for wind energy projects. Though wind energy is a mature commercialized technology internationally, real and perceived financial risk for wind projects remains a significant barrier in Vietnam. This risk results largely from limited experience among local project developers, operators, and debt providers in designing and financing commercial wind projects. This paper details several wind 
project risk considerations, such as the availability of high-quality wind resource data, access to enabling infrastructure (e.g., road and electricity transmission networks), interconnection rules and regulations, permitting, and technology availability. Effective policy design and finance can address these considerations by linking wind development to broader national planning efforts (including infrastructure planning) and by instituting clear incentives and models for sharing risk through joint project development.

Finally, this paper presents recommendations on the technical and policy elements critical to designing successful, long-term roadmaps for wind energy (and broader electricity sector) development. These elements comprise a holistic, analytically based framework that local, provincial, or national planners can adapt to develop a strategy that attracts support and financing from domestic and international actors. An integrated development, energy, and climate change mitigation program can ultimately help provincial and national planners utilize wind power and other renewable energy technologies to achieve sustained GHG reductions as the country develops.

This paper is the result of a collaborative effort between the U.S. Agency for International Development and the U.S. Department of Energy's National Renewable Energy Laboratory and has been developed in support of the U.S. Government's Enhancing Capacity for Low Emission Development Strategies program. 


\section{TABLE OF CONTENTS}

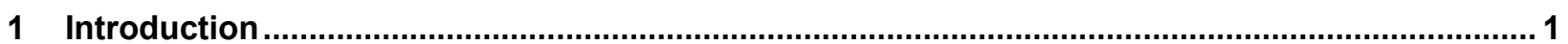

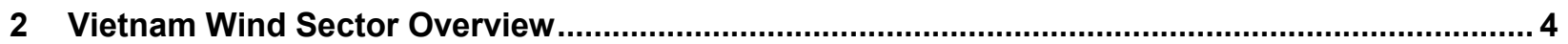

2.1 Vietnam's Current Electricity Sector Profile and Wind Power Potential ....................... 4

2.2 Wind Resource Distribution and Infrastructure Considerations ................................. 5

2.3 Policies Supporting Wind Development in Vietnam .............................................. 6

3 Advancing National and Local Policy Objectives Through Wind Deployment ............................. 8

3.1 Context for Policy Development......................................................................... 8

3.2 Environment and Natural Resource Management.................................................. 10

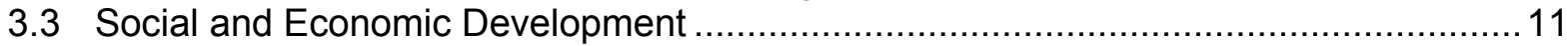

4 Reducing Project Risk and Attracting Finance in the Wind Sector............................................. 14

4.1 Identifying and Mitigating Technology Risk .................................................... 14

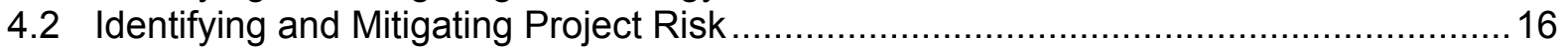

4.3 Effective Policy Design and Finance................................................................... 18

5 Wind Power and Long-Term Low Emission Development and Energy Planning ....................... 21

5.1 National Policy Context for LEDS .................................................................2 21

5.2 Key Elements of Low Emission Development Planning for Electric Power Generation22

References ...................................................................................................................... 27

Appendix A: Implications of Vietnam's Spatial Distribution of Wind on Development Costs........... 30

Enabling Lower-Cost Wind Energy through Infrastructure Planning and Expansion .............32

Enabling Lower-Cost Wind Energy through Land-Use Policy and Planning ..........................33

Appendix B: Illustrative Provincial Analyses...…………….............................................................35

Wind Energy Potential and Opportunities in Quảng Bình Province ................................... 36

Wind Energy Potential in Bạc Liêu Province ............................................................. 38

Appendix C: Vietnam Wind Analysis Annotated Bibliography ....................................................4 4

Appendix D: Geospatial Toolkit National Screening Data ................................................................. 56 


\section{LIST OF FIGURES}

Figure 1. Vietnam wind resource potential at 65-m hub height under land and infrastructure constraints. The generation potential is shown for the combined road and transmission buffer scenarios.

Figure A-1. Wind resource and major transmission and road networks in Vietnam ...................32

Figure A-2. Proximity of best quality wind resources to existing transmission networks in

Vietnam.....

Figure A-3. Distribution high-quality wind resources across various land uses ...................... 34

Figure B-1. Quảng Bình and Bạc Liêu provinces....................................................... 35

Figure B-2. Wind maps of Quảng Bình province, indicating total land area and wind capacity potential under different scenarios. Top left: total wind potential for entire province. Top right: high-quality wind resource (Class 3 or above). Bottom left: high-quality resource, excluding water bodies and urban areas. Bottom right: high-quality resource, excluding water bodies, urban areas, and protected areas.

Figure B-3. Left to right: wind resource, excluding areas having a slope greater than 5\%; districtlevel electrification rate; district-level poverty rate.

Figure B-4. Wind resource sensitivity to road and transmission access. From left to right: highquality wind resource available within $10 \mathrm{~km}$ of 1) roads, 2) transmission lines, and

3 ) roads and transmission lines. Excludes land uses described above.

Figure B-5. Wind map of Bac Liêu province, indicating total land area and wind capacity potential under different scenarios. From left to right: total wind potential for the entire province, high- quality wind resource (Class 3 or better), and high-quality resource, excluding water bodies and urban areas.

Figure B-6. Wind resource sensitivity to land use. From left to right: high-quality wind resource on croplands, grasslands and shrub lands, and barren lands.

Figure B-7. Wind resource sensitivity to road access. From left to right: high-quality wind resource available within $10 \mathrm{~km}, 5 \mathrm{~km}$, and $2 \mathrm{~km}$, respectively, of major roads. .....39

Figure B-8. District-level electrification (left) and poverty (right) rates ................................... 39

Figure D-1. Vietnam wind resource potential (land area): sensitivity analysis .........................56

Figure D-2. Vietnam wind resource potential (generation potential): sensitivity analysis ..........57

Figure D-3. Regional wind resource availability .......................................................5

Figure D-4. Wind resource by region (expressed in square kilometers of land meeting the given

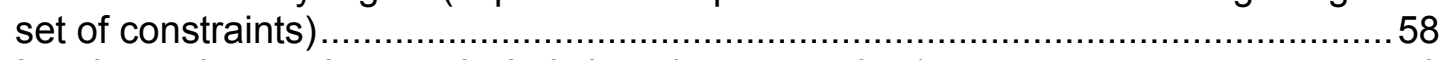

Figure D-5. Land area by province and wind class (no constraints) ..................................59

\section{LIST OF TABLES}

Table A-1. Illustrative Relationship between Capacity Factor, LCOE, and Wind Resource ....... 31

Table B-1. GST Datasets Used for Vietnam .... 


\section{Introduction}

In support of Vietnam's Green Growth Strategy, the U.S. Agency for International Development's Enhancing Capacity for Low Emission Development Strategies (ECLEDS) program collaborated with the Department of Energy's National Renewable Energy Laboratory to better understand the potential for wind energy in the country. The EC-LEDs program provides partner countries targeted assistance to develop and implement their low emission development strategies (LEDS).

This paper seeks to discuss the two primary objectives that strengthen Vietnam's Green Growth Strategy. The first objective is to provide timely and useful information to provincial-level planners, analysts, and project developers as they evaluate opportunities to develop local wind resources. The second is to provide insights to policymakers on how coordinated efforts may help advance large-scale wind development, deliver near-term greenhouse gas (GHG) emission reductions, and promote development objectives, including climate resiliency in the context of a LEDS framework.

The wind sector is the focus of this discussion due to its significant potential in Vietnam, its relative nascent stage of commercial development in the country, and the high potential for wind to advance other priority policy goals as part of Vietnam's Green Growth Strategy. Despite this focus on the wind sector, it is anticipated a number of the policy approaches and considerations discussed may have relevance to other technology or resource sectors under consideration by the Government of Vietnam.

Green growth and LEDS are distinct from traditional development planning due to the explicit emphasis on achieving GHG emission reductions. While social and economic development objectives remain paramount, green growth and LEDS provide a planning framework that seeks to optimize these development benefits while at the same time identifying and advancing cost-effective mitigation opportunities in the near-term with systems and structures for reducing carbon intensity over the long term. Ideally, these frameworks also establish inherent elements of climate resiliency by encouraging the design of infrastructure and supporting systems to anticipate environmental variability and new threats that may be posed by climate change in the coming decades.

With energy serving as a critical building block for economic development and growth, as well as a primary source of emissions, the energy sector plays a central role in LEDS planning. In 2000, the energy sector was the source of 35\% (53 million tonnes of carbon dioxide equivalent) of Vietnam's national GHG emissions, second only to the agriculture sector [1]. Moreover, based on the Government of Vietnam's medium economic development scenario, increased energy demand over the next two decades has the potential to increase emissions from the energy sector nine fold (to 471 million tonnes of carbon dioxide equivalent) by 2030 , making it the fastest growing emission sector in the country.

For policy planners, immediate considerations of cost and energy access for consumers must be balanced with long-term implications of energy infrastructure that will be in place for decades. Regional trends and competition for energy resources further complicate these decisions. For example, strategic questions for Vietnam may include: 
- To what extent should imported electricity from large-scale hydropower development in the Mekong Delta be relied upon, and how will production and access change under climate change scenarios?

- What are the relative trade-offs between energy security and local air quality and GHG emissions as domestic coal reserves are developed?

- What are the optimal uses of domestic natural gas reserves, and how can these be most economically developed?

- To what extent should domestic renewable resources be developed, at what cost, and how can their co-benefits be best monetized?

- How can capacity expansion and future transmission planning optimize complementary base load and peaking generation?

- Can the zero emission potential of nuclear power be cost-effectively and safely developed?

These are complicated, big picture questions that will ultimately guide the direction of Vietnam's growth. Although energy sector focused, each of these questions will also influence national security, climate resiliency, trade and economic competitiveness, social and environmental quality, and development. Again, this report does not seek to address all of these questions but explores issues related to wind development in the context of this broader LEDS framework.

This paper draws upon existing literature on effective practices and experiences gained in the wind sector globally while emphasizing supporting analysis and insights that reflect the unique conditions and priorities of Vietnam. Examples of these unique domestic conditions include: Vietnam's rapid rate of growth in electricity demand and overall economic growth; the emphasis this growth places on energy system reliability and resiliency; the potential for both distributed and utility-scale grid-tied wind development; and the potential for diversity of resources, including both traditional and renewable, that may further complement wind development over the coming decades. In addition, specific barriers and opportunities will likely present themselves in Vietnam due to the limited amount of wind power currently installed in country and the relative absence of a domestic manufacturing base in this technology area. It is hoped these insights and the Vietnam-specific context will make the report more relevant and useful to the target audiences, including policymakers and analysts in Vietnam.

As a zero emissions, commercially viable technology, wind power has a demonstrated track record as an important part of national LEDS in many countries around the globe. Installed wind capacity globally has surpassed 280 gigawatts (GW) in total this year, with a significant percentage of this generation occurring in the developing world. Based on currently available data, Vietnam also has significant wind resource potential that has not yet been developed and that could serve as a significant, complementary domestic resource in support of a diversified, reliable energy mix. At the same time, wind project deployment has been shown to deliver multiple ancillary benefits to national and local economies, including creating jobs, improving energy access, supporting local manufacturing, and resulting in local environmental benefits, such as reduced water demand for energy production. The relative impact of these benefits 
depends in large part on the scale of development and investment but also upon how market incentives and supporting programs are designed.

This paper is organized in sections starting with an initial overview of the current status of wind development and wind potential in Vietnam. This section draws upon analysis conducted using the Geospatial Toolkit (GST) that was developed for Vietnam under the EC-LEDS program. The GST is a data visualization tool that integrates energy resource data with other critical geographical information system (GIS) data, such as transmission, load centers, roads, and land-use classification, to help inform project planning and policy development. Although a key recommendation from this effort carried out with Vietnam's Ministry of Industry and Trade (MOIT)/General Directorate of Energy is the need for continued improvements to, and validation of, wind resource assessment data for Vietnam, these initial GsT analyses focused on quantifying overall wind potential by province, and taking the next critical step of evaluating how much of that theoretical potential could be technically and economically accessed and developed.

The next two sections of the paper evaluate specific issues and opportunities for policy frameworks to accelerate wind development, followed by market and financial considerations that are unique to the wind sector. These discussions are further explored by more detailed discussions of the spatial distribution of wind on project cost in Appendix A and a look at two example provinces in Appendix B. The final sections of the paper provide an overarching perspective on how effective policy frameworks and planning could be used to both accelerate project development and emissions reductions, with an emphasis placed on providing practical guidance to readers on designing robust wind sector development "roadmaps" that can attract international financing, followed by a summary of key conclusions. It is hoped these insights may also help to identify specific capacity building opportunities to support Vietnam's Green Growth Strategy and related initiatives to realize near-term emission reductions while advancing economic growth and development. 


\section{Vietnam Wind Sector Overview}

The wind sector in Vietnam is characterized by significant resource potential, both for off-grid and grid-connected generation, but with a relatively small number of established wind projects. These factors provide Vietnam with a unique opportunity not only to draw upon lessons learned in other countries that have designed successful wind programs at the national and subnational levels, but also to proactively manage these resources through informed policy design and infrastructure planning, potentially optimizing the development and emission-mitigation benefits derived as a result.

\section{I Vietnam's Current Electricity Sector Profile and Wind Power Potential}

Total electricity consumption in Vietnam was 94,000 gigawatt-hours (GWh) in 2011, representing more than a quadrupling of electricity demand from 2000 [2]. The majority of domestic electricity production is currently based on hydropower (50\%), natural gas $(28 \%)$, and coal $(18 \%)$ in total installed capacity. Demand is further projected to triple to 330,000 GWh by 2020, reflecting Vietnam's rapid economic growth [3].

Based on initial analysis using the resource data in the GST, Vietnam's wind potential significantly exceeds its current electricity demand. Across the entire country, theoretical wind potential is over $1,000,000 \mathrm{GWh} /$ year on land where annual average wind speeds exceed 6.4 meters per second $(\mathrm{m} / \mathrm{s})$ at 65 -meter $(\mathrm{m})$ hub height [4]. ${ }^{1}$ The average net capacity factor over these areas is approximately $33 \% .^{2}$ Although these numbers should be viewed only as the theoretical potential, even if strict land use and infrastructure exclusions are considered, the overall potential of wind that could technically be developed would meet a significant portion of current national electricity demand. Under conservative constraints (i.e., resources are within 2 kilometers $(\mathrm{km})$ of both roads and transmission lines and are not on protected, wetland, or urban land), nearly 800 square kilometers $\left(\mathrm{km}^{2}\right)$ of land area with high quality wind resources are still potentially available for development. If all of these resources considered to be "low-hanging fruit" were developed, they could potentially meet about $10 \%$ of Vietnam's current electricity needs (the equivalent of nearly $4 \mathrm{GW}$ of capacity, capable of generating 11,700 GWh/year).

This estimate is a more conservative estimate of theoretical potential than that reported in the 2011 Wind Atlas summary developed by MOIT and AWS Truepower [5], which identified over $200,000 \mathrm{~km}^{2}$ of developable wind resource. However, in general, both analyses support the notion that abundant potential for wind development in the country exists and that the wind resource itself is not likely a limiting factor to growth in this sector. This GST-based assessment is also consistent with an analysis by the

\footnotetext{
${ }^{1}$ An annual mean wind power density over $300 \mathrm{Watts} /$ square meter at $50-\mathrm{m}$ hub height (which equates to an annual average wind speed of $6.4 \mathrm{~m} / \mathrm{s}$ ) is considered an informal threshold for utility-scale wind potential in the United States and is applied as a similar threshold in this analysis. Lower wind speeds than this threshold may be appropriate for smaller-scale distributed generation applications.

${ }^{2}$ Capacity factor refers to the ratio of the annual energy that a system produces to the amount of energy it would have produced if it had operated at its full, nameplate capacity for the entirety of the year. Capacity factors assumed in the GST are based on utility-scale wind technology performance estimated in the United States over 2005-2010 as reported in [29].
} 
Department of Economics at Vietnam's Institute of Energy that identified approximately $3.5 \mathrm{GW}$ of wind that could be developed at less than 6 cents/kilowatt-hour $(\mathrm{kWh})$ based on over $800 \mathrm{~km}^{2}$ of developable wind area identified [6].

Wind resources are also widely distributed regionally across the country. Based on both mesoscale modeling completed by AWS Truepower in 2011 [5], provinces with significant wind resource potential include: Bạc Liêu, Sóc Trăng, Ninh Thuận, and Bình Thuận in the south; and Bình Định, Lâm Đồng, Đắk Lắk, Gia Lai, Quảng Bình, Quảng Trị, and Nam Định in the central and northern parts of the country. Further analysis using the GST also indicated there may be additional provinces where lower wind speed regimes could be accessed for distributed power systems, including Hà Tĩnh, Kon Tum, Quảng Ninh, Lạng Sơn, Nghệ An, and Phú Yên. As the quality and granularity of wind resource assessments improves over time, including a movement toward higher hub heights for utility-scale wind development, it is anticipated the geographic distribution of this potential will increase.

\subsection{Wind Resource Distribution and Infrastructure Considerations}

While the theoretical potential of wind is very large, technical access to, and costeffective development of, these resources will be constrained significantly by varying factors depending on location. For example, the north central coast of Vietnam has a high concentration of roads but relatively limited transmission, while high-voltage transmission and road infrastructure run parallel through the central highlands and south central coast of the country. Figure 1 illustrates how these critical road and transmission constraints impact the overall economic potential for wind that can be developed. This figure shows the degree to which wind resource availability decreases under certain constraints, such as when protected areas and land uses incompatible with development are excluded or when only the resources within a certain "buffer" distance from primary transmission and road arteries are considered (i.e., a 10-km buffer excludes all wind resources outside of a $10-\mathrm{km}$ radius of a road or transmission line). ${ }^{3}$ When considered together (last bar to the right in Figure 1 ), a much more realistic sense of the opportunity for wind development can be gained. The graph also illustrates the critical role that broader infrastructure policy and planning plays in supporting this sector.

\footnotetext{
${ }^{3}$ This analysis is based on the infrastructure data in the Vietnam GST, which includes only the primary high-voltage transmission network (500-kilovolt lines and 220-kilovolt interconnections) and major roads. At this time, publicly accessible, spatially linked data on lower-voltage distribution systems and secondary roads that may further enable wind development is not available for inclusion in the GST for analysis.
} 


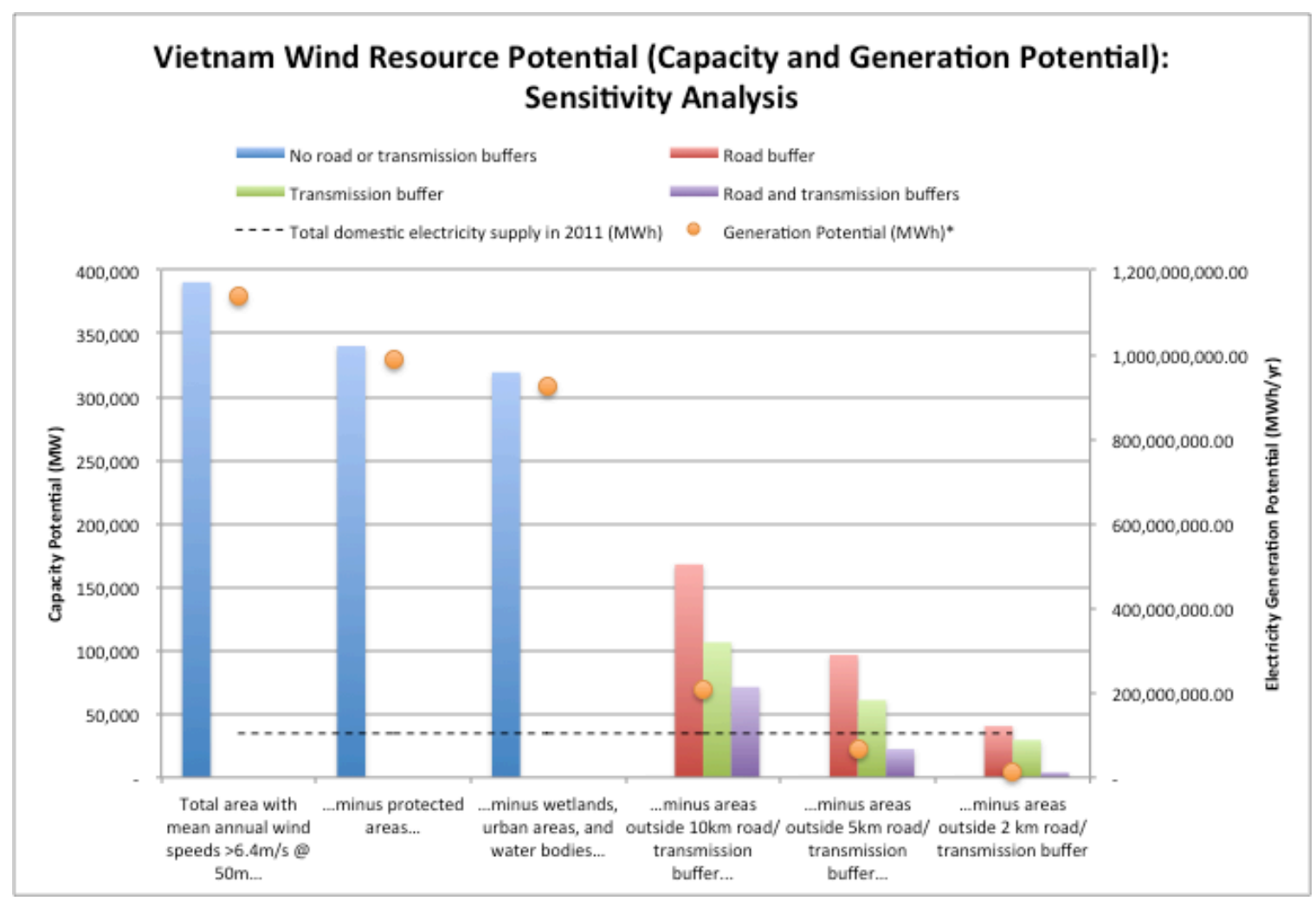

Figure 1. Vietnam wind resource potential at $65-\mathrm{m}$ hub height under land and infrastructure constraints $^{a}$

${ }^{a}$ The generation potential is shown for the combined road and transmission buffer scenarios

As illustrated in Figure 1, proximity to roads and transmission constrains wind potential more than land use. Between the two factors of roads and transmission, proximity to transmission is more of a limiting factor on resource availability overall. Analysis using the GST also suggests that wind resource availability decreases linearly as a function of distance from roads or distance from transmission. When taking into account distance from roads and transmission, the trend is closer to a power function. The implication is that, for all policy levers considered in this assessment, access to areas with both road and transmission is the primary limiting factor on economic wind potential in the country. This is a particular concern for small and medium wind farms (having capacities under 100 megawatts [MW]), where constructing long roads or transmission lines may limit the economic feasibility of the project. As a result, a long-term growth strategy that envisions significant development of the national wind resource must consider this market opportunity in parallel with broader national infrastructure planning.

\subsection{Policies Supporting Wind Development in Vietnam}

Currently, less than $100 \mathrm{MW}$ of total wind capacity has been installed in Vietnam, despite a number of established policy goals for broader use of renewables. ${ }^{4}$ Numerous national level policy documents reinforce the national goal of increased deployment of

\footnotetext{
${ }^{4}$ Including the strategy and master plan for renewable energy development for Vietnam by 2015, which was established by MOIT.
} 
wind energy technologies, including Vietnam's National Energy Development Strategy 2020; Vietnam's Power Development Plan (2006-2015); the draft Strategy and Plan for Renewable Energy Development 2015; and the most recent Green Growth Strategy, which aims for a $20 \%$ - 30\% reduction in GHGs by 2030 against the business-as-usual scenario [7]. Additionally, the National Power Development Plan for the 2011-2020 Period with the Vision to 2030 establishes targets of 1,000 MW of total wind power capacity by 2020 and $6,200 \mathrm{MW}$ by 2030 [8]. This objective also sets targets of a $4.6 \%$ and $6 \%$ contribution from renewable energy sources generally to total electricity generation by 2020 and 2030, respectively, and encourages investment of local power sources to enable electrification in rural areas, mountains, and islands. Additionally, the national energy development strategy establishes targets for renewable energy contributing $5 \%, 8 \%$, and $11 \%$ of total primary energy production by 2020,2035 , and 2050 , respectively [9]. Based on this broad political support, it is clear there is a national vision and intention to expand the deployment and use of wind, both as a contributor to emission reductions and as a key source of economic flows within an emerging green economy. The more critical challenge now is putting this vision into practice in a costeffective, efficient, and sustainable manner.

At the subnational level, a number of provinces have also demonstrated political leadership on the topic of clean energy development, including wind, such as: Ninh Thuận, Bình Thuận, Bạc Liêu, Lâm Đồng, Bà Rịa-Vũng Tàu, and Phú Yên. Bình Thuận has also taken additional steps by developing a province-level wind development plan over the period of 2009-2015 with a long-term vision out to 2020 [10]. This vision and leadership at the local level can provide extremely valuable insights on local barriers, as well as best practices for other provinces or districts seeking to expand wind deployment in their region.

With political momentum at both the national and subnational levels, integrated planning presents a number of unique opportunities to evaluate this resource potential in the context of existing and emerging policy frameworks, as well as by the unique geographic or capacity constraints that may hinder growth in the sector. This evaluation can be accomplished through making logical connections where development priorities can be advanced by deploying clean energy technology solutions that will directly reduce the GHG emissions intensity of the power sector. This coordinated approach will also help ensure more carbon-intensive generation infrastructure is not locked in over the long-term when less carbon-intensive and economically viable electricity generation options may be available. 


\section{Advancing National and Local Policy Objectives Through Wind Deployment}

Integrated planning in the wind sector can support a variety of policy objectives and goals. At a smaller distributed scale, wind power can help provide cost-effective power for economic development for rural communities not currently served by the grid. For example, over 1000 small-scale wind systems have been installed in Vietnam in the range of $100-500 \mathrm{~W}$ in size over the last three decades. In the majority of cases these have been demonstration projects in partnership with the GVN and local research institutions such as the Research Center for Thermal Equipment and Renewable Energy (RECTERE) of the Ho Chi Minh City University of Technology, the Institute of Energy, or the Hanoi University of Technology (HUT). The smaller systems in this range (150W) at a cost of around $\$ 270$ USD have tended to be most popular for the delivery of basic electricity needs at the household level [11]. On a larger scale, captive power needs for remote industrial applications, such as mining, can be met by distributed wind systems coupled with other energy sources. As the sector expands and utility-scale grid-tied wind power grows, broader national goals can be served, including reduced reliance on imported fuels, greater diversity of supply, and increased local manufacturing capacity for local or export markets. To maximize the policy benefits of these outcomes, a broader policy framework must be developed with an informed vision of which outcomes, beyond just megawatts of wind installed, are desired.

\section{I Context for Policy Development}

Examples of effective, sustained, and impactful wind development are often, if not always, tied to a long-term strategic approach that is rooted in both sound policy and fiscal measures. The strongest examples that further stand out are those where wind deployment targets are directly integrated with other social and economic objectives. For example, utility-scale development of wind in many U.S. states has served an important part in advancing local objectives of revitalizing rural communities or regions that were economically depressed. Through linking these mutually supportive policy goals, a broader stakeholder base can be established in support of the sector and scarce financial resources more easily leveraged at both the national and local levels.

A policy design that optimizes the use of available resources, including people, land, water, energy, and capital, is a fundamental lever for decision-makers to advance their domestic LEDS or green growth strategy. When local or provincial plans are in harmony with national goals, the policies are reinforcing. For example, local strategies may be established for meeting a specific target for economic growth in a local district. These local strategies will be inherently tied to providing reliable energy services in support of that growth. At the same time, if a national energy plan includes targets for clean energy development, a local province may be able to benefit from this national program as it seeks to exploit its local wind resource through financial, technical, or political cooperation.

This broader perspective is critically important as it can help leverage other policy initiatives or investments and build broader stakeholder support for wind development in segments of the populace that may not have any awareness, interest, or knowledge of 
opportunities in the power sector. In the other direction, the extent to which the design of national-level policy frameworks can draw explicit linkages to issues of local interest, such as climate resiliency, job creation, and energy access, a national level initiative will likely be more successful. This is ultimately the most critical measure of a green growth strategy or LEDS in that it is ideally responsive to explicitly defined economic development priorities while also delivering measurable GHG emission reductions.

Looking beyond provincial or national boundaries, policymakers may also benefit from assessing which goals can be accomplished unilaterally versus where wind deployment could be accelerated through coordinated policy or other actions nationally with international cooperation. Specific examples of international cooperation are explored in more detail in this paper but examples include: working with donors or private entities for improved or more detailed wind resource assessments; financial support for initial wind sector incentives, such as targeted subsidies for small wind systems; or technical cooperation with wind sector developers and financiers to establish initial "anchor" wind farm projects to support broader market growth. A number of recent collaborative studies with donors and other technical institutions also provide very useful examples of the types of cooperation already underway. A few examples of this type of international cooperation that is sector-specific include: a Deutsche Gesellschaft für Internationale Zusammenarbeit (GIZ) and MOIT Guideline on Wind Power Planning in Vietnam [11]; a GIZ/MOIT Report on Wind Power Development and Financing [12], and other less recent but still very useful reference documents that provide detailed insights on specific aspects of advancing wind in Vietnam.

As policymakers consider alternative policy designs to support wind development, various approaches will likely deliver different social, economic, and market outcomes depending the type, duration, and scale of the policy measure. For example, the feed in tariff (FIT) structure has proven to have a demonstrable impact on near-term deployment of wind, especially where FIT structures have represented a significant financial incentive relative to the established price of electricity. At the same time, a FIT may have relatively minimal impact in supporting off-grid wind development or the ability to attract investment for local manufacturing if the scale of project opportunities nationally is limited in scale. For a country like Vietnam, with a relatively modest amount of wind power currently developed, the greater potential for local manufacturing may be more oriented toward export markets rather than domestic demand. As a result, fiscal incentives through policy should be cognizant of the likely outcomes and quantifiable benefits before significant national investments are made in supporting a specific policy measure.

The duration and perceived continuity of a given policy can also lead to major differences in outcomes in practice beyond just the amount of total new capacity installed. For example, in the United States, the production tax credit (PTC) structure has been vital to dramatic growth in the wind sector, but investment has not necessarily been optimized because there was great uncertainty on the extension of this credit due to Congressional review and approval. At the same time, the PTC structure was established at a national level and significant enough in scale that it provided sufficient market incentive for both project development but also local manufacturing when coupled with renewable portfolio standards (RPS) in specific U.S. states. Clarity in the 
design, length, and ramp down of any policy incentive is critical in providing clear market signals to project developers and investors.

Economic development and competitiveness are primary drivers for all nations. At a provincial or district level, this factor is even more critical as local planners seek to advance job creation, training, and economic flows in their local communities.

Depending on the size and economic status of the regional unit, the economic development priorities will vary significantly. For a province with energy access challenges, a primary focus may be on distributed applications of wind power to support rural energy access and reliable supply of power for small-scale industry and job creation. Vietnam has experience in this area over the last two decades implemented primarily through $R \& D$ programs targeting rural energy needs in coastal, mountainous and island areas with over 20 wind-solar hybrid systems, 120 wind turbines, and 4,000 solar systems deployed by 2012. Tariff structures for these projects are guided by Decision No. 37/2011/QD-TTg on supporting mechanism for developing wind power projects in Vietnam and must be conform to the master plans of both wind power development and power development approved by authorized agencies [11]. For another province with good road and grid access, the focus may be more on the potential for attracting investment and creating a manufacturing base for products or services related to the energy sector broadly or the wind sector specifically. Being realistic about the scale of this investment and the project's potential, as well as the resulting economic flows, is critical, particularly in local markets that may still be relatively small in scale even if all wind penetration targets are met or exceeded nationally.

Investments in the wind sector also create opportunities for workforce development and training. This outcome can be further advanced if policy and incentives reward project design where investments in the local community support local job creation. For example, investments may include longer-term operation and maintenance (O\&M) positions for wind farm management and manufacturing and related services if broader based investment is anticipated [13]. The workforce development and training aspects of a vibrant wind sector also lend themselves to broader stakeholder engagement that could be facilitated as part of a larger national strategy for training and workforce education. In particular, important roles can be played by: academia, vocational training programs, international donor initiatives that emphasize training, or industry partners that may help better define the specific capabilities they are seeking in the marketplace.

\subsection{Environment and Natural Resource Management}

In addition to GHG mitigation objectives, wind power development can play a critical role in advancing other national or subnational environmental goals. Depending on broader natural resource management or environmental objectives, integrated planning that incorporates wind can emphasize specific policy outcomes. For example:

- Water resource management. Many developing countries, including Vietnam, are highly dependent on domestic watersheds to provide multiple environmental and economic services to food production, power production, potable water, and industrial uses. Unlike many power generation technologies, wind power uses little to no water, thus reducing demand on this precious resource. For a district 
or province where water constraints are already present or are anticipated to grow under climate change scenarios, wind can serve as a viable alternative to other thermal or renewable technologies that may be significantly more water intensive on a per kilowatt-hour generation basis.

- Land-use management and natural resource optimization. For agriculturally based economies, effective watershed management is a fundamental aspect of sustainable development. In addition to the environmental and economic services outlined above, watershed management affects and is affected by many other policy considerations, including infrastructure development, transportation planning, and urban planning. As energy development options are considered, there are numerous upstream (mining, agriculture, power production, competing demands for land use, etc.) and downstream (water quality, water temperature, competing demands for water, etc.) impacts at play. A particular agriculturerelated benefit of wind energy is the small amount of land that is displaced from production by utility-scale wind farms: average permanent direct impact has been estimated at $0.3 \pm 0.3$ hectare per megawatt of wind capacity, which includes the land devoted to both turbine pads, as well as access roads and electrical support equipment [14]. Therefore, depending on how wind development is incentivized and how siting is determined, integrated resource management goals may benefit, including watersheds management.

- Local environmental quality. Local air and water quality considerations are critical to human health and social well-being, and in many cases, have shown to have a measurable negative economic impact as local environmental conditions decline. Polluted air and water can raise health costs, reduce agricultural productivity, and create disincentives for investment in local economies. The environmental attributes of both utility scale and distributed wind lend themselves to integrated local and national strategies related to improved local air quality, water conservation, and water quality. Sector-specific issues related to wind and impacts on biodiversity are being increasingly explored to inform siting and management practices to mitigate negative effects on biodiversity, including birds and bats. ${ }^{5}$

- GHG mitigation. As a zero GHG-emitting technology beyond those associated with manufacturing and installation, wind can play a significant role in a province or nation's goal of providing reliable power while mitigating GHGs. In some cases, these emission reductions can also provide an additional financial flow to support the economics of a particular project based on the carbon credits associated with that effort. Power generation infrastructure can have very long lifetimes (upward of 50 years in the case of some thermal technologies) that may lock-in a country to specific choices for decades to follow, which may be convenient today but may be less advantageous in years to come.

\subsection{Social and Economic Development}

Social and economic development priorities are the building blocks for low emission development or green growth strategies. The success and sustainability of any policy

\footnotetext{
${ }^{5}$ For a detailed examination of these issues, see Greening the Wind: Environmental and Social Considerations for Wind Power Development. Washington, DC: World Bank, 2011.
} 
will ultimately be measured by the direct benefits it delivers to the citizens. In this light, it is critical the programs or policies designed to support wind project development incorporate, and advance, the local priorities of the region where the development will occur. Often it is the local officials, with input from a variety of stakeholders, who will have the greatest insight on these factors, because the priority needs may differ significantly from district to district and province to province. Although social and economic benefits can be measured and advanced in many ways, a few specific contributions directly associated with the wind sector are discussed below.

- Energy access. A reliable and affordable power supply is critical to establishing and expanding an industrial base and for attracting investment for new commercial enterprises. Both grid-tied wind power, as well as distributed minigrid systems that integrate wind, can make important contributions to reliable power, particularly in those cases where rural energy services may be inadequate or where reliance on imported diesel is unreliable or cost-prohibitive. Compared to many other renewable energy technologies, wind has demonstrated an ability to be directly competitive with traditional energy resources, including natural gas, when the project is of sufficient size and sited in a strong wind resource area.

- Stemming urban migration. Reducing urban migration through rural development can be supported both by providing economic opportunity and jobs in local communities. Where appropriate, wind and other local resources can contribute to these national objectives both by providing power to underserved communities but also supporting jobs related to that industry. This serves as a specific example where local project development and incentives can support broader national-level policy objectives.

- Agricultural productivity. For a national economy heavily dependent on domestic agricultural production like Vietnam, the ability for energy policy and project development to complement agriculture economy needs and priorities is also very important. Distributed wind systems in particular can play a role in hybrid systems along with biomass residues and related feedstocks from that agricultural sector although hybrid examples to date in Vietnam have been wind/diesel and wind/solar rather than integrating a biomass component. In addition, smaller-scale wind systems have a demonstrated track record in both the developed and developing world for agriculture-based applications, including water pumping.

- Poverty reduction and economic growth. Initial analyses using the GST indicated that in many provinces, there is an overlap of developable wind resources and a relatively high incidence of poverty or lack of access to reliable power. Distributed wind systems that complement or hybridize existing microgrids or provide new energy services can advance socioeconomic priorities, such as human health, energy access, and related social services. As policy planners design their own rural development strategies, energy (including distributed wind systems) can be a key element of this effort. This can extend to broader job creation and economic benefits if local industry begins to emerge around this sector. 
- Disaster risk management. Climate resiliency and proactively reducing specific risks to climate change are an increasing area of focus for municipalities and local communities in both the developed and developing world. Depending on how wind development is structured and sited, this technology can either exacerbate these risks or help strengthen disaster management strategies. For example, if planning does not consider potential geohazards, such as flood or landslide zones, areas exposed to typhoons, or sea level rise, these policies may incentivize wind development in inappropriate areas. At the same time, diversification of the energy portfolio that includes spatial diversity of generation, generation that may complement other generation sources that may be more water intensive, or increased use of distributed generation, can directly support disaster risk management strategies over the long term. Although all energy technologies should be considered in this approach, wind can play an important role in advancing each of those objectives.

- Energy security. Diversity of supply and the optimal use of domestic energy resources is an important element to achieving energy security. As a domestic, renewable resource, wind also has zero fuel cost. As a result, a policymaker has less exposure to fuel price escalations or imposed restrictions on supply from outside entities, including electricity imports from hydro or thermal stations that may be a greater risk under extreme climate scenarios. While this aspect may be less of a factor for economies where wind will stay a relatively small part of the overall energy mix, it can be a very significant driver for off-grid or distributed systems that are primarily dependent on imported diesel for electricity generation. Where possible, this energy security consideration should be integrated into wind development planning, particularly for mini-grid or other distributed generation schemes.

Considering priority development benefits, along with the GHG mitigation benefits of wind technology deployment, allows for policy design and implementation to better optimize outcomes in both of these areas. At the same time, coordinated policy design can help identify near-term opportunities for engagement and collaboration with academia, non-governmental organizations, industry, and international partners. For example, multiyear infrastructure and transmission planning is critical to successful long-term wind strategies, and locating transmission through high wind resource areas can stimulate renewable investment in a specific geographic region. Long-term transmission and other infrastructure planning also has a direct impact on watershed management, land use and urban planning, and rural development outcomes, which could all be strengthened when examined alongside wind development considerations. Integrated planning for energy could also help establish and clearly communicate the specific capacity building needs that support improved policy analysis, development impacts assessment, or other elements that inform long-term policy planning and successful design or implementation of these policies. 


\section{Reducing Project Risk and Attracting Finance in the Wind Sector}

As evidenced from past experience in both the developed and developing world, policy design and other measures can directly reduce the risk associated with wind project development. While technology risk is always a consideration, wind is a commercially viable and field-proven technology at both the small, distributed scale and at the utility scale. Although any specific technology solution still needs to be vetted and should be supplied by a trusted vendor with clear warranties for the product, wind tends to have fewer risks on this front as compared to other technologies that have had a shorter commercial track record. That said, financial risk for wind projects is still a major barrier, particularly in countries like Vietnam where there have been fewer commercial projects developed, fewer local debt providers experienced with this technology, fewer largescale projects deployed, and a relatively limited experience in the operation and maintenance requirements of these systems domestically. This section identifies some of the opportunities for Vietnam in identifying and mitigating these risks, as well as to provide initial insights on how policy efforts could be coordinated to better attract finance and investment in this sector. Appendix $\mathrm{C}$ of this document also provides links to a variety of additional resources for more detailed information on these topics that may be useful to policy planners, projects developers, and energy project financiers.

\section{I Identifying and Mitigating Technology Risk}

Identifying and reducing technology risk is a critical element at both the individual project level but also for broader provincial or national-level planning where a specific technology, or portfolio of technologies, is being advanced. In some cases, these risks are very real, particularly for a technology without a long track record of performance and commercialization in general or where the supplier of a specific technology has not demonstrated field reliability in specific applications. In the case of both small, distributed wind systems and larger utility-scale turbines, the market benefits from the fact this is a mature and commercially established technology with a diversity of reliable vendors and established O\&M protocols. In addition, all established technology suppliers offer warranties for these systems that generally exceed the payback period for most projects. Furthermore, a wealth of experience has been gained over the last decade for optimizing wind farm design, development, and power production in both the developed and developing world.

While these attributes of the wind power sector greatly reduce the potential for encountering these technology risks, Vietnam will still likely face two specific barriers at both the provincial and national level as it seeks to grow its nascent wind sector. First, perceived risk by local debt providers that may not have had exposure to, or experience with, these technologies, which can be further exacerbated by concerns over the project developer and their ability to deliver, the credit of the off-taker, and grid transmission access. Most large projects require a combination of equity investment, as well as the provision of debt from local banks. This second community has historically been more challenging to convince on the merits of wind technology even when a commercially proven technology is being proposed, siting issues have been addressed, and validated wind resource data is provided. Capacity building efforts and stakeholder engagement 
that directly engages this community can be critical to the long-term success of both individual projects, as well as broader national strategies for advancing wind. As more successful projects are completed and showing financial returns, this barrier will become less of an issue as evidenced in other countries where wind has gained a significant share in the overall energy mix and where mature credit markets exist.

A second category of likely barriers that may be relevant to Vietnam or other developing economies where wind is not yet fully established are those cases where real technology risk is encountered. Examples may include scenarios where: less reliable vendors are promoting a specific turbine or blade design that may not yet be commercial; new technologies or methodologies are being developed locally and piloted; projects were sited poorly due to any number of reasons; where appropriate, site-specific resource assessments were not conducted; or where a viable business model that incorporates required O\&M was not established. Each of these factors can doom an individual project but also tarnish the reputation of a sector as a whole.

As a result, it is critical for policy planners to have a long-term perspective on the many underlying factors that can increase or mitigate these risks. Further, these issues must be addressed through active and regular engagement of a variety of stakeholders, including utilities, the finance community, project developers, local communities, academia, and technical institutions. Each of these communities will bring unique and valuable perspectives to the table, and these multi-sector approaches have been fundamental to the growth of the wind sector in countries like China, Denmark, Germany, India, and the United States. Although these are larger countries and economies, the underlying issues and challenges for local deployment of wind projects is often very similar across all countries, developed and developing.

An earlier lesson learned that directly relates to technology risk and is tied to policy design is the fundamental question of which aspect of the wind project is supported or incentivized. In other words, do the financial incentives reward hardware in the ground measured by installed capacity or are benefits received based on how much actual energy is produced by those projects? Ultimately, the most important outcome is to have electricity generated reliably and cost-effectively. This "production" component is critical to both the economic viability of a specific project or farm but also important to the overall success of the market as a whole as efficient and productive wind farms reflect well on the reputation of the technology. An emphasis on production, generally through mechanisms like a PTC or FIT not only rewards the actual generation of electricity but also inherently promotes an additional emphasis on effective O\&M and establishing a viable business model for the project. While there are other international examples of policy incentives that emphasize investment, this can lead to rapid growth in a sector and hardware in the ground, but not necessarily to projects that are sustainable, economically viable over the long term, or productive [15].

Integrated policy design and implementation must always weigh the relative benefit and cost of any investment of public resources. This is true in any country, but particularly relevant in an emerging economy like Vietnam where a decision-maker has many competing demands for the investment of precious financial and human resources. Fiscal incentives for any technology imposes a cost on the country as a whole, which is ideally outweighed by the other social benefits and positive externalities generated, 
such as local jobs, leveraging further investment and economic growth in that sector or region, cleaner air and water, enhanced energy security, and reduced GHG emissions. That said, policy and financial analysis is critical to ensuring a clear target for wind penetration is established, and the technology is not "over-incentivized" and that a clear plan for phasing out incentives over time is established. This is not an easy calculation, and again, flexibility but clarity in the approach and assumptions, as well as active involvement in the dialogue to affected entities, including the utility, project developers, financiers, and regulators, are critical. Further, the type, size, and duration of fiscal and policy incentives may be different, depending on the specific wind application and project size so these unique attributes should be considered as the policy framework is developed.

As noted above, establishing and meeting international standards for wind farm O\&M is critical to both project performance and in establishing a successful market for wind more broadly. This factor also helps raise the credibility of the sector for both local debt providers, as well as for domestic and international entities considering investments in wind or other competing technologies. While O\&M protocols are relatively wellestablished for utility-scale wind projects, the standards for smaller-scale, distributed systems are less robust. In those cases where a district or province may be considering wind an important component to their rural energy strategy, the critical component of O\&M should be emphasized, including the requirement to ensure trained personnel are available and financially incentivized to provide these services. This element is often directly tied to the overall business model for the off-grid system and where a solid O\&M plan can be mutually reinforcing if integrated into that business plan. As the sector grows nationally, the trained workforce consideration becomes even more important and can, at the same time, complement national strategies around vocational training and employment.

\subsection{Identifying and Mitigating Project Risk}

Identifying and reducing project risk is a second broad category that extends beyond technology risk and reflects the many policy, regulatory, and environmental conditions that may impact the viability of a specific wind project or farm. Most, if not all, of these risks are not unique to the wind sector or to energy development in Vietnam, but will be critical to any policy approach or other local initiatives to accelerate wind deployment in the country. Appendix $\mathrm{C}$ includes a host of information and links to reports with more detailed information on specific risks, barriers, and strategies for addressing these common issues in the wind sector. While local policymakers and analysts will want to explore these reports more extensively, specific barriers that may be particularly relevant to Vietnam's wind sector are explored below.

Barriers to implementation of wind projects in Vietnam can take many forms and will likely evolve as the market matures and as the socioeconomic conditions in the country change. As evidenced by both the initial GST analyses for Vietnam and further supported by international experience, effective wind development is heavily dependent on land-use considerations, including identification of high-wind resource areas, access to those locations, supporting infrastructure for developing those resources (including road and rail), and proximity and access to existing or planned transmission and distribution. At the same time, land-use planning must weigh a multitude of 
considerations and a number of often competing priorities, including urban growth, agriculture, mining, watershed management, natural resource management, and biodiversity, among others. As a result, integrated planning can provide effective frameworks for transparently weighing these trade-offs and articulating a clear, longterm vision for development and economic growth.

In respect to addressing these considerations in the context of wind development specifically, high-quality resource data to support efficient wind "prospecting" serves as a critical foundation for developing a national wind strategy. As specific zones or regions are then identified, site-specific wind data collected for at least one year is also critical to ensuring that underlying resource will deliver capacity factors in the range of $30 \%$ and up to ensure cost-effective delivery of electricity. This underlying need for high-quality wind resource data cannot be overemphasized, as it is one, if not the most, critical factor in lowering the levelized cost of energy of a wind project. Policy activities, technical assistance, or industry collaborations that can advance and improve on available resource data can be key contributions to addressing this barrier. Further use of these data and integration into tools like the GST that allows for these resources to be visualized and analyzed along with other critical GIS layers like load centers, roads, and transmission can further support informed policy development and planning.

As noted above, even if they are identified and quantified, excellent wind resources may not be economically or technically accessible due to lack of key infrastructure, which includes passable roads, land slope, environmental restrictions, or proximity to high voltage transmission. This is particularly relevant to large, utility-scale projects where blade size and foundation requirements require access for heavy-duty vehicles and transport. As a result, while the theoretical potential of a wind resource may be large for a given location, the technical and economic potential (in other words, the quantity of the resource that can be cost-effectively developed) may be significantly smaller. This consideration is explored in more detail in the province-level case studies in Appendix B. Integrated land-use planning and consideration of available energy resources, both renewable and thermal, should ideally be accounted for in broader land use, transmission, and urban planning (e.g., appropriate turbine setbacks from homes, schools, and roads), or in the development of comprehensive planning efforts to ensure that all relevant resources are being considered in meeting growing energy demand.

At the site level, streamlined systems for managing the permitting and siting provisions for wind projects are critically important to reducing or increasing the costs of project development. Environmental protections, regulatory statutes, and other social priorities must be maintained but efforts to improve the efficiency of permitting and review processes can significantly reduce the direct costs to project developers, accelerate the pace of project development, and generally improve the operating environment for project developers. Additionally, nationally defined permitting processes can help avoid local opposition. For a country like Vietnam, where the initial size and number of projects may be limited, these are particularly important considerations for policymakers and regulators. At the same time, planners and regulators that are developing wind strategies or reviewing applications for wind project development should ensure any unique local environmental factors are included, such as geohazards like flood zones, typhoon exposure, sea level rise or storm surge, or operating wind systems in harsher 
maritime, coastal environments. For nations that are especially vulnerable to climate change, these constraints may increase in scope or geographic coverage over time.

Transmission access on fair and equitable terms is also a critical requirement for largescale wind development. This is not simply a question of proximity to the grid network but clear, regulatory guidance for interconnection and the structure of power purchase agreements to ensure a fair price for electricity provided. Again, Appendix $\mathrm{C}$ provides a more detailed discussion of these issues, including regulatory considerations unique to the wind sector, technical and policy issues surrounding interconnection, and alternate approaches for addressing the variability of the wind resource. Each of these issues directly affects the viability of projects, as well as the sustainability of national strategies for broader wind sector development. As a result, it is critical a diverse group of stakeholders is brought into the discussion for policy formulation and that transparent rules and guidance are established.

Although the global nature of the wind industry lends itself to ready access to wind technology suppliers generally, for smaller economies without established wind markets, the constraint of technology availability may still be a concern. Vietnam is in a unique position in that although its current installed capacity of wind is still relatively small, a significant resource potential exists. Growing electricity demand and an emerging policy environment tied to the country's Green Growth Strategy will likely be very attractive to wind developers and project suppliers. That is a considerably different situation than in a smaller economy, where the long-term potential for the market is relatively small and may be less attractive to developers. With this constraint in mind, policymakers may want to focus initial activities and sector support initiatives in particular regions where critical mass for a market can be established and where significant wind resources exist. The first few hundred megawatts of capacity are always the hardest to achieve because this is where developers and suppliers face the greatest risk and uncertainty before the sector matures.

As the market grows in size and scale, the capital costs of this technology will likely be driven down and in turn help drive down the levelized cost of energy for new projects, assuming they are sited well and the financial structures are effective. This trend also helps to attract additional investment as financiers and developers see a viable and profitable market emerging for wind. Further, ancillary service providers may be encouraged to start up or grow to advance the local economies where multiple projects are located. These benefits can happen at a local level as a specific province advances its wind market or at a national level as multiple districts and provinces see growth in the sector.

\subsection{Effective Policy Design and Finance}

At the country level, utility-scale wind resources are often viewed as a valued national asset. With this perspective, policy and regulatory frameworks should be established so that 1) renewable investors have certainty in the permitting process and investment returns and 2) this national resource can then be most cost-effectively developed and the related benefits, both economic and social, can be maximized. Drawing the connections across these various objectives is again where a green growth strategy or LEDS framework may be advantageous in helping to make logical connections between 
a diversity of policy drivers and outcomes that may not be readily apparent at first or where the coordination of multiple governmental entities is required.

Some specific considerations that may be most relevant to Vietnam include national policy objectives related to accelerating economic growth, ensuring energy security, and advancing climate resiliency. In respect to national goals for sustaining Vietnam's rapid economic growth, linking high-wind resource potential areas to zones targeted for industrial growth, those with an anticipated increase in population, or where reliability of existing energy resources may hamper continued growth could be advantageous. Further, identifying where significant co-benefits can be derived through wind development, such as rural electrification, meeting captive power demands of local industry, or addressing local air quality considerations, may further complement regional or national policy plans for economic development.

As Vietnam's energy mix becomes more diverse over time, wind may also be able to play an important role in overall plans for capacity expansion. Opportunities for increased cross border trade of power in future may also benefit from the integration of wind as a hedge against variability in hydropower production under future climate change scenarios. This reliance on a domestic, renewable resource can also insulate a province to some degree from future fuel price volatility related to traditional fuels, such as natural gas, coal, and diesel fuel. Distributed generation systems can also provide greater geographic diversity that may be advantageous if particular regions are affected by climate or other environmental change at any given time.

Linking infrastructure development planning or timing of implementation to energy development initiatives will also be critical for a developing country like Vietnam. Rapid growth in capital stock and growing energy demand will require near-term implementation of policy initiatives but ideally in the context of a long-term framework for planning that reflects optimal use of all available energy resources and integrated climate resiliency. Again, this will help ensure growth can be maintained and the development of national resources can be staged in a way to make the most economic and optimal use of these resources. Ideally, these national plans also provide a coherent linkage of provincial plans to ensure local initiatives are complementing each other and making the most optimal use of limited human and financial resources, including foreign investment. This approach can also potentially draw upon lessons learned and best practices from leading provincial plans, especially those that are demonstrating success on the ground.

Coherent, long-term policy roadmaps for wind development that are further supported by clear incentives, regulatory expectations, and active support from the local or national utility is also critical to attracting finance for large-scale wind development. This has been evidenced in numerous national and subnational cases where rapid growth in the wind sector has occurred. In practical terms, these types of investment-friendly frameworks include conditions such as established and consistent requirements governing interconnection of variable resource like wind to the grid; standard power purchase agreements or transparent processes for bidding on wind development concessions; officially sanctioned policies that establish and deliver on any fiscal incentives for project development; and clear policy signals that may impact the cost or 
timing for project development, such as additional incentives or cost-sharing related to land acquisition, local manufacturing, or workforce training.

Models for joint project development and sharing of risk can also be a potential approach to demonstrating the viability of wind in a province and raising the confidence of investors for future projects. For example, in Sri Lanka the national utility invested in an initial 3-MW wind pilot project to assess the viability of wind in that country and to learn about the challenges and opportunities for integrating a variable resource like wind on to the transmission and distribution system. This pilot also provided valuable insights on the importance of accurate siting of wind farms to maximize output that, in turn, influenced future wind concessions and planning. These types of staged approaches can significantly reduce the cost of future project development, provide practical experience for both the project developer and the utility, and raise confidence of future investors on the local and national commitment to the development of this sector. 


\section{Wind Power and Long-Term Low Emission Development and Energy Planning}

This paper has presented insights on strategies for promoting economic development and achieving significant reductions in GHG emissions in Vietnam through the development of wind power. In this section, the authors expand upon this material to present some of the key technical and policy elements that should be considered in the development of a successful, long-term LEDS for electric power generation. Such an approach can help provincial and national planners utilize wind power and other renewable energy (RE) sources effectively to achieve sustained GHG reductions through an integrated development, energy, and climate change mitigation program.

\section{I National Policy Context for LEDS}

In Vietnam, the country has made a key first step in this regard by setting a target for wind and other renewables. Under the Power Master Plan VII, electric power generation from these sources is planned to increase to $4.5 \%$ of total generation in 2020 and $6 \%$ in 2030 , with wind capacity to rise to $6,200 \mathrm{MW}$ by 2030 . This action could serve as the basis for a long-term transition to RE sources, an essential component of an effective LEDS. Ideally, under a LEDS framework, energy resource planning will include a blueprint for steadily increasing the proportion of energy demand met by such sources over a long time frame until the associated generation accounts for a significant share (e.g., a majority or more) of the total. In addition to achieving a range of development benefits discussed earlier (e.g., rural development, improved air quality) at the local level, achieving a high rate of RE penetration will have important broader climate change mitigation benefits. At the national level, it will contribute to the efforts of countries to successfully meet national GHG reduction targets they may set for future years; at the international level, it can make an important contribution to the achievement of the global reductions necessary to limit global temperature increases to 2 degrees Celsius.

This section aims to elaborate concepts that are important for the development of effective and integrated low emission electric power generation systems in Vietnam and other developing countries, identify potential areas of near-term capacity building, and provide a long-term vision to assist provincial-level implementers in the design of LEDS plans. In addition to incorporating GHG mitigation best practices into electric grid management, development of a program based on the elements discussed here can also assist development and energy officials with planning and managing the grid more effectively in areas not directly related to climate change policy. The following caveats should be noted however:

- This approach presents a comprehensive and ideal framework for LEDS planning, and some of these steps will likely be beyond the current capabilities of many regions. Implementation of these elements would, in any case, need to be tailored and adapted to fit the specific needs of each district, province, or country.

- While this paper focused on implementing wind power at the provincial level, some of the elements presented here may be most appropriately (or currently are) conducted in developing countries at the national level. This is particularly 
true for Vietnam given the current structure of its electric power sector, with Electricity of Vietnam (EVN) as the sole power distributor. However, RE development under a LEDS will require considerable local involvement for areas such as siting, permitting, monitoring, and maintenance; provincial planners and LEDS developers will also benefit from exchanges of information in these areas with their national counterparts. This section is therefore presented with the assumption that any long-term RE transition program would be developed with both national- and local-level involvement and coordination.

- Vietnam currently has a single, integrated national power grid. With the government's intention to reform and create a competitive power market, it is conceivable that separate regional power markets could be developed in the future (this process may be further encouraged if international integration with power markets in neighboring countries is expanded). The authors have therefore included guidance in some areas that could be appropriate, should such changes be undertaken.

\subsection{Key Elements of Low Emission Development Planning for Electric Power Generation}

In this section, key elements that local, regional, and/or national planners should consider in their efforts to achieve a transition to RE in the electric power sector are presented.

- Long-term projections of electric power demand (central and off-grid): The first step in efficient, long-term grid management is the development of estimates of demand for electric power in future years, for both the province and the surrounding grid (regional or national) of which the province is a part. A number of methodologies and platforms exist for undertaking such analyses, which typically develop projections based on population growth, urbanization patterns, gross domestic product growth, fuel price estimates, transmission availability, industrial output, etc. This analysis should also incorporate long-term projections of expansion of off-grid demand and proportions of such demand to be connected to the grid in future years.

- Assessment of technical potential of renewable energy in province (or region): Assessments of the total potential capacity of location-specific $R E$ sources (i.e., wind, solar, small hydro, geothermal) in districts and provinces can be conducted using site and national surveys, as well as assessment tools such as the GST. These assessments are key in setting an upper bound as to the maximum amount of demand that can be met with such sources. In the case of carbon-neutral biomass, this source can be obtained from wood plantations, as well as industrial (i.e., pulp and paper) operations. Supplies are limited only by land availability and quality, and can therefore be grown to make up potential "deficits" of other renewable capacity for use in steam turbines, combined heat and power units, and advanced gasification systems, where economically viable based on competing uses of land resources and biomass transport constraints. 
Utilizing biomass from new plantations also has the additional benefit of removing and sequestering carbon from the atmosphere.

- Screening of renewable capacity potential: As seen in this paper, some RE supplies are unlikely to be developed due to technical factors, such as distance from roads or transmission, location in protected or sensitive areas, inaccessible terrain, etc. Provincial LEDS planning should conduct analyses similar to the wind screening presented here for the available RE sources. These analyses should aim to account for potential changes that could impact such availability in future years, such as planned completion of transmission lines, large-scale infrastructure development, population expansion and movement to new areas, land-use planning, etc.

- Addressing potential transmission and distribution losses: In many developing countries, significant amounts of power are lost during transmission and distribution (T\&D). In Vietnam, T\&D losses are estimated to be in the range of $10 \%$ for the national grid [16]. LEDS planning should evaluate the efficiency of existing T\&D systems and explore actions to minimize losses. This will improve general grid operations and help reduce the quantity of fossil-fired generation needed to meet future demand.

- Cost analysis and modeling of emission scenarios: The above data can then be combined with more general electric power data and information (e.g., existing electric-generating capacities and fuels, estimated cost of new build fossil and RE technologies, dispatch decision methods, etc.) to develop and model future emission scenarios. These will include one or more business-asusual or reference cases (see more on this below), as well as policy cases with the impact of different levels of both RE and energy efficiency (EE) penetration. For LEDS planning, such scenarios can help set targets for RE development in specific years based on factors that include costs, emission levels, RE technologies and types, available resources relative to demand, etc.

- Reference case development: One of the key outputs from the above modeling is a reference scenario that estimates the types of generation to be employed to meet demand at specific times, absent any additional policy intervention. The results can be used to develop insights on anticipated future load profiles and duration curves that show estimated levels of baseload versus peak power capacity demand, plus the associated fuels and specific plants that may be used to meet such demand. These are often complex and data-intensive analyses that are highly dependent on anticipated capacity expansion planning and future generation requirements. As a result, a system for the regular revising and updating of forecasts is important.

- Training and capacity building on estimating displaced emissions: LEDS planning and implementation in the electric power sector should aim to maximize the emission reductions obtained from RE generation and EE. A first step in this process involves analysis (or more advanced modeling) of the regional (or national) power grid to estimate the fuel type most likely to be displaced at any given time [more sophisticated models may be able to estimate the specific type of generating technology or unit to be displaced as well (i.e., the marginal unit)]. 
Such analysis can also help estimate whether existing generation or new build capacity will be displaced by clean energy actions.

- Policy design to maximize GHG mitigation benefits: Based on the displaced emissions analysis, RE and EE support policies can then be designed to target the highest-emitting sources to facilitate maximum GHG reductions and to prevent competition between different low- or zero-emission energy sources and between RE and EE. For example, in areas where the highest emitting fossil sources are utilized during peak hours, programs can be specifically designed to provide higher incentives for RE generation or electricity saving at those times. LEDS planners may also consider adapting programs to support specific types of $\mathrm{RE}$ depending on the grid emission profile-in areas where a substantial proportion of baseload power is met by coal, for example, RE programs could target projects with high capacity factors (i.e., geothermal or hydro) to maximize displacement of this fossil fuel. In provinces or jurisdictions that include multiple distinct power grids, EE and RE development can be targeted to the grid where the highest emitting sources will be displaced (as noted earlier, this is not currently the case in Vietnam's single national power market). Designing policies to maximize reductions in fossil fuel consumption will have the added benefit of increasing the air quality and other development co-benefits achieved from clean energy actions.

- Inform and refine policies to support clean energy: The above quantitative analyses can help inform the design of effective policies to support RE for GHG mitigation. For example, future projections of electric power prices and RE supplies can help design graduated and targeted tariff or price subsidies, with appropriate and cost-effective incentives tailored to the specific circumstances in each time period. At the national level, financing and trade policies can encourage importation of higher performance wind turbines and other RE technologies. For example, fiscal incentives to promote joint ventures, foreign investment, or reduced tax burden on imported hardware can be critical to jump starting a market using the best available technology.

- Regional analysis to assess emissions leakage: An important component of provincial LEDS in the power sector is evaluation of electricity imports and exports. Changes in the differences in power prices, capacity availability, and other factors can, in turn, alter transmission flows between jurisdictions; depending on the fuel mix of the respective grids, this can produce emissions leakage, wherein emission reduction actions in one province or jurisdiction cause emissions in a neighboring one to increase. In cases where leakage appears likely to be significant (for example, when two interconnected jurisdictions have similar cost and price profiles), the relevant analysis and evaluation would ideally be conducted on a regional (or national) basis, allowing the emissions impact in the implementing jurisdiction to be compared with the overall net impact.

- Grid integration: In electric power grids where generation from variable RE sources (e.g., wind, solar, etc.) is low, such sources can typically be connected to the grid with only minimal changes to existing infrastructure and management. As the share of such RE generation increases, however, maintenance of effective grid function and performance may require upgrade and technological 
improvements to prevent power shortages and blackouts, minimize wasted or dumped power, etc. Existing grids can typically handle about $10 \%$ or so of total generation from variable sources; beyond this level, the grid will begin experiencing difficulties. A large body of evidence further shows the cost of intermittency is high for isolated and smaller grids, but this cost is almost eliminated when renewables are combined with grid expansion, a "smarter grid," and demand side management [22, 23, 24]. While a detailed discussion of these processes is beyond the scope of this paper, national and provincial LEDS planners can minimize the potential problems associated with variability by planning for necessary grid improvements (based on projected levels of wind and other variable RE generation) well in advance, under different possible scenarios. This will help ensure advanced grid integration is begun soon enough to allow a smooth continuation of the transition to RE, minimizing any time lag for wind or solar deployment. Such preparation can also improve general grid performance and ease the effective utilization of other nonrenewable sources (e.g., natural gas-fired combustion turbines) needed during the transition to RE.

- Resource and adaptation monitoring: LEDS planning for a large-scale transition to RE will also benefit from regular scientific monitoring of changes in the key natural resource inputs to renewable power generation (average wind speeds, solar energy intensity, river flows), to enable accurate assessments of the supply of renewable electricity likely to be available currently and in future years. Down the road, cutting-edge LEDS can be further enhanced by combining such efforts with adaptation monitoring to include the potential regional and local impacts of climate changes on RE generation. Under such a framework, grid managers would coordinate and share data with adaptation monitors, so that predicted changes in wind patterns and other variables resulting from climate changes can be included in long-term planning (this should be coupled with tracking of climate change impacts on generation from fossil-fired capacity as well). This will enhance the short-term forecasting methods currently employed by utilities and large wind farms for both specific sites and broader grid management.

- Institutional coordination: In each province or jurisdiction undertaking LEDS, effective planning and implementation will require coordination among institutions and officials within and between different levels of governance. Horizontal coordination between institutions will facilitate cooperation among those officials involved in general electric power grid management and those in other key areas identified above as essential to RE assessment and development (e.g., mapping and supervision of protected and other sensitive areas, land-use planning, natural resources monitoring, etc.). Vertical coordination among district, provincial, and national institutions can facilitate joint collection and sharing of data relevant to RE, help streamline licensing and permitting, and ensure consistency of information, reporting formats, etc. (note that although in a number of developing countries data on land use and renewable resources are already monitored and collected, they may not be widely shared or adapted for use in the electric power sector). Vertical coordination will also assist in identifying and improving opportunities for RE development in off-grid areas. At the regional level, both the analysis and implementation phases of provincial 
LEDS will ideally include collaboration between institutions in interconnected provinces. This will help officials develop policies to address GHG emissions leakage, assess changes in air quality, etc.

- Monitoring and supervision of the LEDS process: In addition to existing institutions, LEDS at both the provincial and national levels will benefit from development of new processes or institutions to monitor and evaluate the above processes over time. These would track and report findings on a regular basis, and would make recommendations to refine the analyses and suggest improvement to LEDS programs. 


\section{References}

[1] Viet Nam's Second National Communication to the United Nations Framework Convention on Climate Change. Socialist Republic of Viet Nam, Ministry of Natural Resources and Environment, 2010. http://unfccc.int/resource/docs/natc/vnmnc02.pdf.

[2] "Vietnam: Electricity and Heat for 2010." IEA Statistics, 2013.

www.iea.org/statistics/statisticssearch/report/?\&country=VIETNAM\&year=2010\&product =ElectricityandHeat.

[3] "Vietnam Country Analysis Note." U.S. Energy Information Administration, 2013. www.eia.gov/countries/country-data.cfm?fips=vm.

[4] Short, W., Sullivan, P., Mai, T., Mowers, M., Uriate, C., Blair, N., Heimiller, D., and Martinez, A. Regional Energy Deployment System (ReEDS). NREL/TP-6A20-46534. Golden, CO: National Renewable Energy Laboratory, 2011. www.nrel.gov/analysis/reeds/pdfs/reeds documentation.pdf.

[5] Wind Resource Atlas of Vietnam, AWS Truepower, LLC, 2011

[6] Nguyen, K.Q, Wind Energy in Vietnam: Resource assessment, development status and future implications, Energy Policy, 2004.

[7] Viet Nam National Green Growth Strategy. Pg. 2. The Socialist Republic of Vietnam, 2012. www.greengrowth-elearning.org/pdf/VietNam-GreenGrowth-Strategy.pdf.

[8] Approval of the National Master Plan for Power Development for the 2011-2020 Period with the Vision to 2030. The Socialist Republic of Vietnam, 2011. www.nti.org/media/pdfs/VietnamPowerDevelopmentPlan2030.pdf? $=1333146022$.

[9] An overview of Vietnam's renewable energy policies and incentives is provided in Nam, P. K., Quan, N. A., and Binh, Q. M. Q. (2012). "Investment Incentives for Renewable Energy in Southeast Asia: Case study of Viet Nam. http://www.iisd.org/pdf/2013/investments incentives viet nam.pdf.

[10] Preliminary Information for Wind NAMA Paper. entec ESCO Vietnam, 2013

[11] Guideline on Wind Power Planning in Vietnam. Deutsche Gesellschaft für Internationale Zusammenarbeit/Ministry of Industry and Trade, 2011.

[12] Report on Wind Power Development and Financing. Deutsche Gesellschaft für Internationale Zusammenarbeit /Ministry of Industry and Trade, 2012.

[13] Understanding Renewable Energy Businesses: Aligning Renewable Energy Firms and Economic Developers. International Economic Development Council, 2013. www.iedconline.org/clientuploads/Downloads/edrp/IEDC Renewable Energy Business es.pdf. 
[14] Denholm, P., Hand, M., Jackson, M., and Ong, S. Land-Use Requirements of Modern Wind Power Plants in the United States. NREL/TP-6A2-45834. Golden, CO: National Renewable Energy Laboratory, 2009. www.nrel.gov/docs/fy09osti/45834.pdf.

[15] Design and Performance of Policy Instruments to Promote the Development of Renewable Energy: Emerging Experience in Selected Developing Countries.

Washington, DC: The World Bank, 2012.

http://elibrary.worldbank.org/doi/book/10.1596/978-0-8213-9602-5.

[16] "Electric power transmission and distribution losses (\% of output)." The World Bank, 2014. http://data.worldbank.org/indicator/EG.ELC.LOSS.ZS.

[17] Short, W., Sullivan, P., Mai, T., Mowers, M., Uriate, C., Blair, N., Heimiller, D., and Martinez, A. Regional Energy Deployment System (ReEDS). NREL/TP-6A20-46534. Golden, CO: National Renewable Energy Laboratory, 2011. www.nrel.gov/analysis/reeds/pdfs/reeds documentation.pdf.

[18] “Vietnam: Balances for 2011.” International Energy Agency, 2013. www.iea.org/statistics/statisticssearch/report/?country=VIETNAM\&product=balances\&y ear=2011.

[19] Decision No. 539/QD-TTg of April 1, 2013, approving the list of extremely miserable communes in the coastal and island areas in the period 2013-2015. The Socialist Republic of Vietnam, 2013.

[20] Nguyen, K. "Wind energy in Vietnam: Resource assessment, development status and future implications." Energy Policy (35:2), 2006; pp. 1505-1413.

[21] Decision No. 221/QD-TTg of February 22, 2012, approving the master plan on socio-economic development of Bạc Liêu province through 2020. The Socialist Republic of Vietnam, 2012. http://faolex.fao.org/docs/pdf/vie113236.pdf.

[22] "Levelized Cost of New Electricity Generating Technologies." Institute for Energy Research, undated. www.instituteforenergyresearch.org/levelized-costs-of-newelectricity-generating-technologies.

[23] Hybrid Mini-Grids for Rural Electrification: Lessons Learned. Alliance for Rural Electrification, undated. www.ruralelec.org/fileadmin/DATA/Documents/06 Publications/Position papers/ARE Mini-grids - Full version.pdf.

[24] Fraunhofer Institute for Solar Energy Systems ISE. (2013). "Levelized Cost of Electricity Renewable Energy Technologies Study" Freiburg: Fraunhofer ISE.

[25] REN21. (2013). "Renewables 2013 Global Status Report." Paris: REN21 Secretariat.

[26] Nguyen, K.Q, Wind Energy in Vietnam: Resource assessment, development status and future implications, Energy Policy, 2004. 
[27] Nam, P. K., Quan, N. A., and Binh, Q. M. Q. Investment Incentives for Renewable Energy in Southeast Asia: Case study of Viet Nam. International Institute for Sustainable Development, 2012. http://www.iisd.org/pdf/2013/investments incentives viet nam.pdf.

[28] "Transparent Cost Database." Open Energy Information (en), 2014. Accessed Jan. 1, 2014: http://en.openei.org/wiki/Transparent Cost Database.

[29] Cost and Performance Data for Power Generation Technologies: Cost Report. Black and Veatch Holding Company, 2012. http://bv.com/docs/reports-studies/nrel-costreport.pdf. 


\section{Appendix A: Implications of Vietnam's Spatial Distribution of Wind on Development Costs}

Provincial and national planning can help to stimulate cost-effective wind energy, in part by encouraging the development of the country's best wind resources. The cost of generating wind power depends on several factors, including turbine technology and size, operation and maintenance (O\&M), and performance. Levelized cost of energy (LCOE) is a metric that uses these lifecycle considerations to estimate the cost of electricity generation on a per kilowatt-hour (kWh) basis. The typical LCOE for utilityscale onshore wind farms in non-Organisation for Economic Co-operation and Development countries ranges between USD 0.04-0.16/kWh [25]. For household-scale systems (turbine size 0.1-3 kilowatts [kW]), LCOE ranges between USD 0.15-0.35/kWh or higher.

The LCOE depends in part on how much electricity a system generates, which is reflected by a capacity factor for a given technology. Capacity factor is the ratio of the annual energy that a system produces to the amount of energy it would have produced if it had operated at its full, nameplate capacity for the entirety of the year. For renewable resources, such as wind and solar, capacity factors account for the natural variability in the resource, as well as operational practices.

Given a predefined turbine and set of operating practices, the capacity factor-and the electricity generation potential — of a wind power facility depends largely on wind resource availability. Wind farms on sites having higher than average wind speeds have higher capacity factors (and lower LCOEs) because they generate more electricity relative to similar systems sited in areas with lower wind resources due to the minimum cut in speed required for most turbines to begin generating power. Choosing sites with excellent wind resource potential for wind energy development is therefore critical to developing cost-effective of wind power.

Table A-1 provides an illustrative example of how capacity factor and LCOE can vary according to wind resource availability. Because of the relatively nascent state of wind energy in Vietnam, very little country-specific data is available on the costs of utilityscale generation. The LCOE in this example is calculated using the following assumptions, which are based on global literature:

- Overnight capital cost: USD 1,700/kW installed

- Fixed O\&M cost: USD 23.7/kW-yr

- Variable O\&M cost: USD 0.00645/kWh

- Discount rate: $10 \%$ 
- Project lifetime: 20 years [20] $]^{6}$

These simplified, illustrative calculations below do not factor financing or discount issues, or future replacement and degradation costs, which project developers could include in a more thorough, complex analysis. Costs of extending transmission and connecting to the grid are also not included.

Table A-1. Illustrative Relationship between Capacity Factor, LCOE, and Wind Resource

\begin{tabular}{|c|c|c|c|c|}
\hline Wind Class & $\begin{array}{c}\text { Wind power density } \\
\text { (W/m² at } 50 \mathrm{~m} \text { above } \\
\text { ground level) }\end{array}$ & $\begin{array}{c}\text { Wind } \\
\text { Speed }(\mathrm{m} / \mathrm{s})\end{array}$ & $\begin{array}{l}\text { Capacity } \\
\text { factor }\end{array}$ & $\begin{array}{l}\text { Simplified LCOE } \\
\text { (USD/kWh) }\end{array}$ \\
\hline 3 & $300-400$ & $6.4-7.0$ & $32 \%$ & 0.078 \\
\hline 4 & $400-500$ & $7.0-7.5$ & $36 \%$ & 0.070 \\
\hline 5 & $500-600$ & $7.5-8.0$ & $41 \%$ & 0.062 \\
\hline 6 & $600-800$ & $8.0-8.8$ & $44 \%$ & 0.058 \\
\hline 7 & $>800$ & $>8.8$ & $46 \%$ & 0.056 \\
\hline
\end{tabular}

Source: Wind class, power density, and speed are from [17]. Capacity factor for onshore wind technology in 2010 is from [29]. Simplified LCOE has been calculated by NREL based on the assumptions described in this section and the calculation methodology described at www.nrel.gov/analysis/tech lcoe documentation.html.

The example in Table A-1 demonstrates that wind resource quality can significantly influence the cost of developing wind power. Retail prices for electricity in Vietnam in 2011 and 2012 were approximately USD $0.06-0.063 / \mathrm{kWh}$, so this analysis indicates wind may be particularly cost-effective in areas with Class 5 or higher resources (though retail prices are expected to rise to USD $0.08-0.09 / \mathrm{kWh}$ by 2020 , which may make lower class wind areas more cost-effective) [27]. Though the actual costs of developing a particular wind project should be based on detailed models and up-to-date market data, the relationship between cost and wind resource has implications for high-level policymakers and planners. Specifically, this relationship underscores 1) the importance of encouraging local or international project development in high-resource areas to establish working models for wind development in Vietnam and 2) the value of maintaining and publicizing detailed wind resource datasets that can help prospectors and other wind stakeholders identify areas of high potential. Two additional examples of ways that high-level planning can enable lower-cost wind development are described below.

\footnotetext{
${ }^{6}$ Fixed O\&M, discount rate, and project lifetime are based on values assumed for wind development in Vietnam as described in [26]. Overnight capital cost is a based on [25], which estimates current capital costs of onshore wind farms to be $\$ 1,750$ - $\$ 1,770$ in major markets (e.g., in Europe and North America), and \$925-1,470 in China and India. The capital cost estimate is also corroborated in [27], which describes Vietnam's subsidies as being based on the assumption that investment costs for wind farms range between $\$ 1,700-2,250 / \mathrm{kW}$, depending on the quality of the technology. Variable O\&M cost is based on U.S. data, as reported in [28].
} 


\section{Enabling Lower-Cost Wind Energy through Infrastructure Planning and Expansion}

Figure A-1 shows Vietnam's wind energy resources relative to major transmission and road arteries. Although Class 3 (wind speeds of 6.4 meter per second [m/s] at $50-65$-meter [m] hub heights) is generally considered to be a lower threshold for utilityscale wind development, the LCOE calculations presented above indicate that better performance, and therefore lower lifecycle costs, can be realized by siting wind in areas with Class 5 and higher resources. Vietnam has over 3,000 square kilometers $\left(\mathrm{km}^{2}\right)$ of land characterized by wind Classes 5 or greater that is not on wetlands, urban areas, water bodies, or protected areas. However, much of this resource is located along the northern and central coasts, and cost-effective development of these resources may be limited by access to infrastructure, such as roads and transmission. Because the costs of extending roads and transmission lines are generally born by the developer, siting wind farms near existing infrastructure is an important economic consideration. ${ }^{7}$

Figure A-2 shows the proximity of Class 5,6 , and 7

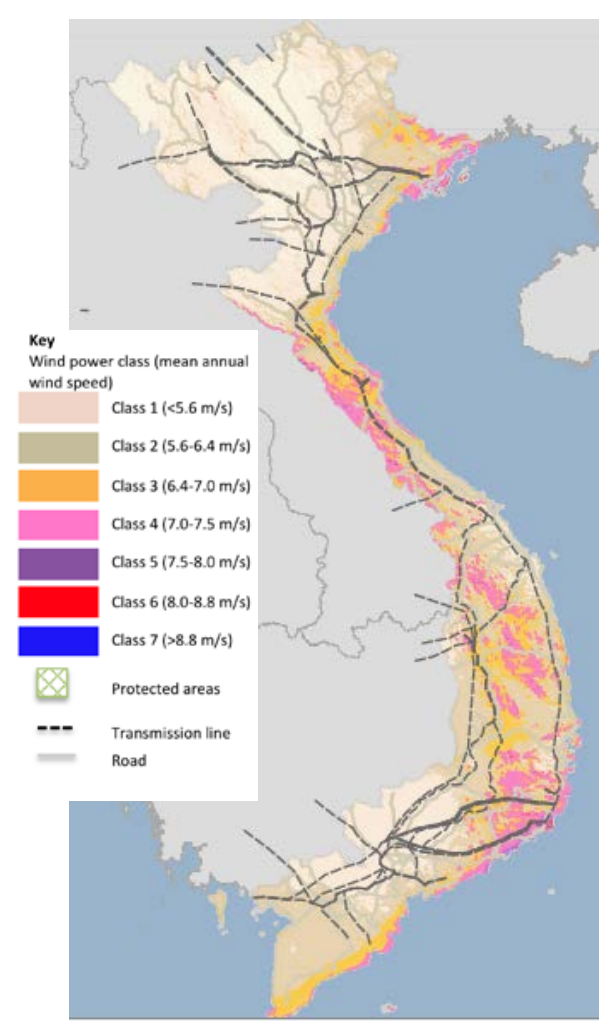

Figure A-1. Wind resource and major transmission and road networks in Vietnam wind resources to high-voltage transmission lines. At the national level, over $95 \%$ of utility-grade wind resources within 2 kilometers $(\mathrm{km})$ of existing transmission and roads are Class 3 or Class 4 (LCOE USD 0.078/kWh and 0.070/kWh, respectively). Only about $200 \mathrm{~km}^{2}$ of land having Class 5 or better wind resource are within $2 \mathrm{~km}$ of transmission lines (and only $30 \mathrm{~km}^{2}$ of this area are also within $2 \mathrm{~km}$ of major road infrastructure). Developers may be discouraged from exploiting Vietnam's higher-quality wind resources because the costs of infrastructure extension needed to access these resources.

\footnotetext{
${ }^{7}$ In the United States, for example, transmission line costs have been estimated at USD 1,200-1,500/MW-mile, not including regional cost multipliers, substation, and interconnection costs [17].
} 


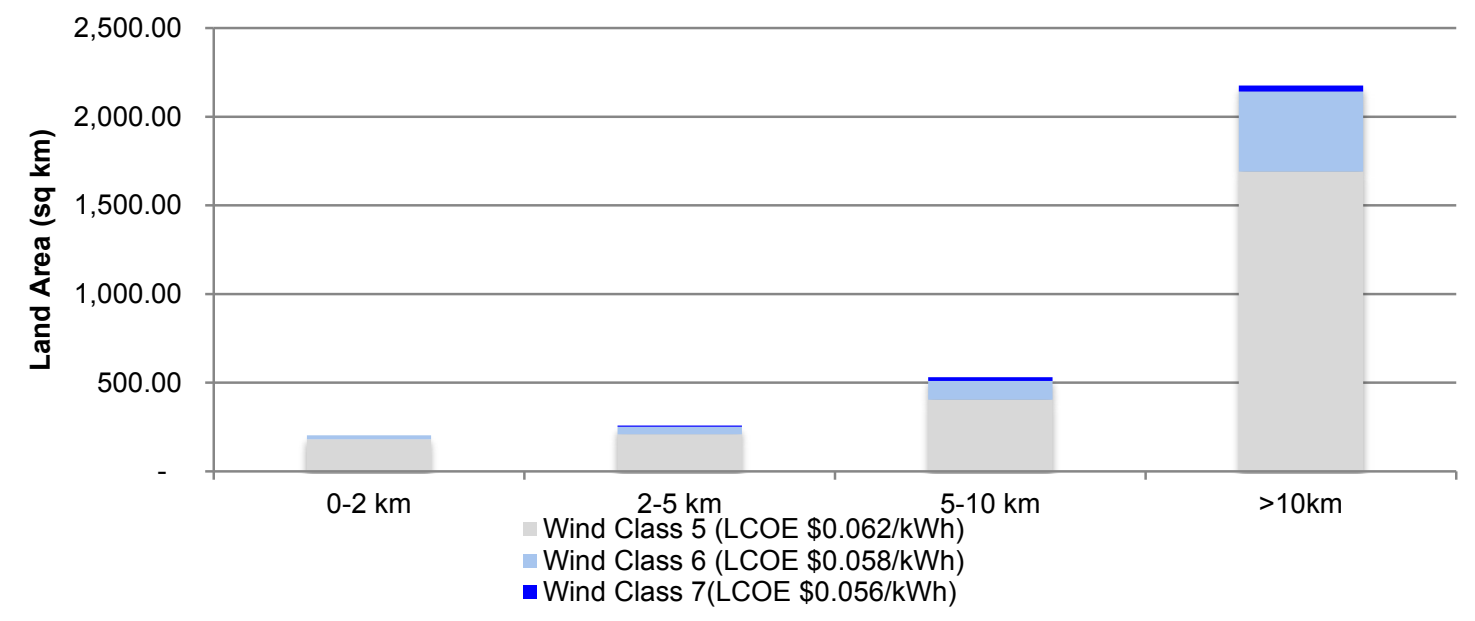

Figure A-2. Proximity of best quality wind resources ${ }^{a}$ to existing transmission networks in Vietnam

${ }^{a}$ Excludes wind resources on protected lands, wetlands, urban areas, and water bodies

National and provincial planners can play an important role in helping project developers access higher-quality resources for development by considering wind energy development in infrastructure planning and implementation. Where expanding infrastructure overlaps with other development objectives, such as economic revitalization, extending transmission and roads to high-wind areas can also improve access to lower-cost energy resources. For example, relative to the resources available within a 2-km transmission buffer:

- Extending transmission lines by 2-5 km in provinces such as Bình Thuân, Gia Lai, Lâm Đồng, Ninh Thuận, and Quảng Bình could facilitate access to up to an additional $250 \mathrm{~km}^{2}$ of primarily Class 5 (LCOE USD $0.062 / \mathrm{kWh}$ ) resources.

- Strategically extending transmission lines by 5-10 km could facilitate access to up to an additional $600 \mathrm{~km}^{2}$ of Class 5 resources, as well as $175 \mathrm{~km}^{2}$ of Class 6 and 7 resources (LCOE $0.056-0.058 / \mathrm{kWh}$ ). A $10-\mathrm{km}$ buffer nearly quintuples the availability of these higher-quality resources relative to the 2-km buffer. Key provinces include Bắc Giang, Bình Thuận, Lâm Đồng, Ninh Thuận, and Quảng Bình.

- Over the longer term, extending transmission beyond $10 \mathrm{~km}$ of existing infrastructure could enable access to over $2,000 \mathrm{~km}^{2}$ of highest-quality wind resources, including in provinces that are currently transmission-constrained (e.g., Khánh Hòa, Kon Tum, Quảng Ninh, and Quảng Trị).

Though Figure A-2 focuses on transmission, access to excellent wind resources can be similarly encouraged through extension of transportation infrastructure, such as roads.

\section{Enabling Lower-Cost Wind Energy through Land-Use Policy and Planning}

Beyond influencing infrastructure, national and provincial planners can also encourage the development of cost-effective wind power through strategic land-use policy and 
planning. Figure A-3 shows the distribution of Vietnam's Class 5, 6, and 7 wind resources across various land-use categorizations, based on data in the Vietnam Geospatial Toolkit. The data excludes areas that are technically limited from wind development by high-slopes or by their categorization as wetlands, water bodies, or urban areas. Nearly half of these highest-quality resources are located on areas that are classified as protected under international agreements as defined by the World Conservation Union. Another 40 percent are located on croplands, with the remainder on grasslands, forests, and barren areas.

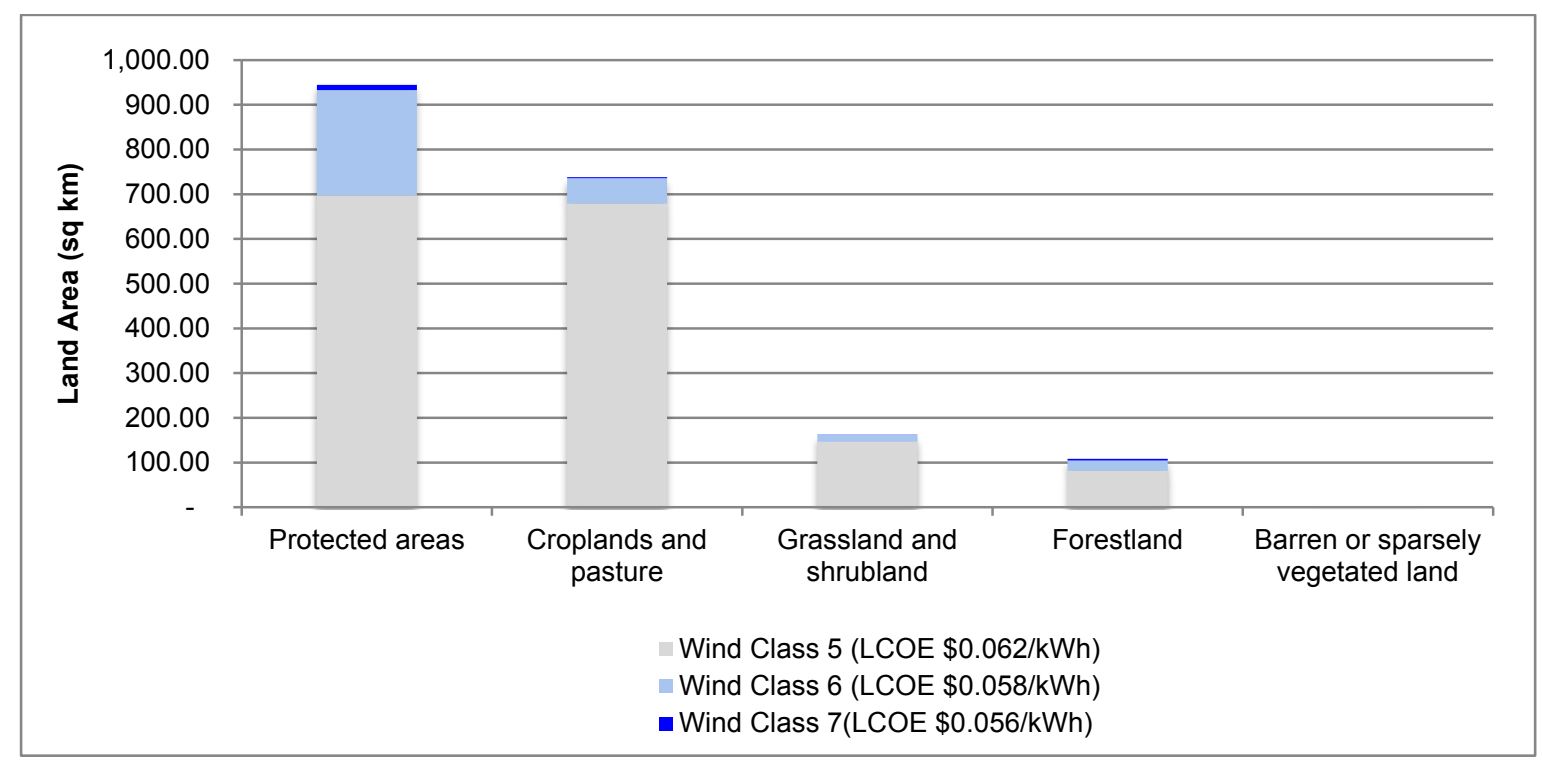

Figure A-2. Distribution high-quality wind resources across various land uses ${ }^{a}$

${ }^{a}$ Excludes wetlands, urban areas, and water bodies and areas with slope greater than $5 \%$

Depending on the specific land uses (e.g., type of crop, level of protected status), wind development may be compatible with either protected areas or croplands. In fact, on croplands specifically, wind energy may be able to meet the captive energy needs of agricultural infrastructure, such as storage and processing, which could support the growth of the sector based on clean energy. Policies that are carefully constructed to allow conscientious wind development in appropriate areas could help developers access:

- Up to 700,680 , and $150 \mathrm{~km}^{2}$ of Class 5 (LCOE USD 0.062/kWh) wind resource on protected lands, croplands, and grasslands, respectively

- Up to 250,60, and $15 \mathrm{~km}^{2}$ of Class 6 and Class 7 (LCOE 0.056-0.058/kWh) wind resource on protected lands, croplands, and grasslands, respectively.

Other land issues, such as tenure, can also be considered and addressed through a comprehensive policy framework that encourages wind power development while contributing to other development priorities. 


\section{Appendix B: Illustrative Provincial Analyses}

This section provides examples of how spatially based analysis of wind resource potential can inform policy design in two provinces: Quảng Bình and Bạc Liêu (see Figure B-1).

These analyses were conducted using the Vietnam Geospatial Toolkit (GST), which was developed in 2013 under the Enhancing Capacity for Low Emission Development Strategies (EC-LEDS) program. The Vietnam GST is a map-based software application that enables visualization and targeted analysis of renewable energy resource data alongside other data of interest, such as land use, roads and transmission lines, and socioeconomic indicators. The GST's query functions facilitate the exploration of the impacts of different constraints—such as site suitability and infrastructure availability-on technical and economic renewable energy potential. ${ }^{8}$

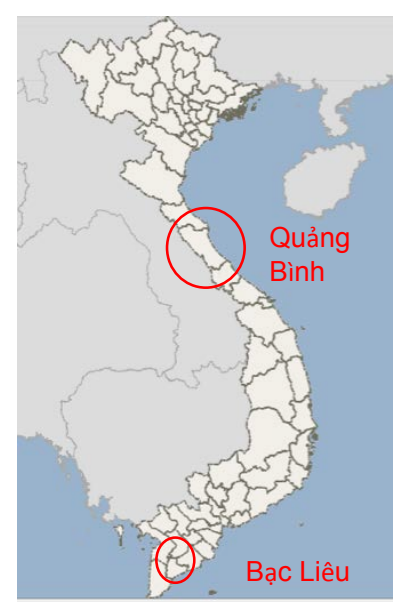

Figure B-1. Quảng Bình and Bạc Liêu provinces

The primary GST datasets drawn upon for this analysis are listed in Table B-1, as are the sources for these data. Given the age and resolution of some of the datasets, this analysis should be treated as high-level and illustrative of a possible framework for approaching wind opportunity identification in two very different provincial contexts. Thorough planning efforts at the province or national levels should be checked against current conditions.

Table B-1. GST Datasets Used for Vietnam

\begin{tabular}{|c|c|c|}
\hline GST Data Layer & Description & Data Layer Provider (Vintage) \\
\hline Wind resource & $\begin{array}{l}\text { 1-km resolution annual mean wind power } \\
\text { density at } 65-\mathrm{m} \text { hub height above ground } \\
\text { level }\end{array}$ & NREL and AWS Truepower (2007) \\
\hline Transmission lines & Utility electric transmission lines & $\begin{array}{l}\text { Digitized from JETRO National Energy Grid } \\
\text { Map (2010) }\end{array}$ \\
\hline Roads & Major road network & Digital Chart of the World (1992) \\
\hline Protected areas & $\begin{array}{l}\text { Database of protected areas of World } \\
\text { Conservation Union categories I through VI, } \\
\text { other protected areas and areas defined } \\
\text { under international agreements }\end{array}$ & $\begin{array}{l}\text { World Database on Protected Areas } \\
\text { Consortium, copyright World Conservation } \\
\text { Union and UNEP-World Conservation } \\
\text { Monitoring Centre (2012) }\end{array}$ \\
\hline Land use & $1-\mathrm{km}$ resolution land use/land cover dataset & U.S. Geological Survey (1993) \\
\hline Elevation & $\begin{array}{l}1-\mathrm{km} \text { resolution terrain elevation in meters } \\
\text { and derived percent slope }\end{array}$ & U.S. Geological Survey (1993) \\
\hline Electrification rate & District-level electrification ratio & $\begin{array}{l}\text { International Food Policy Research Institute } \\
\text { (2005) }\end{array}$ \\
\hline Poverty rate & District-level poverty rate & $\begin{array}{l}\text { International Food Policy Research Institute } \\
2005\end{array}$ \\
\hline
\end{tabular}

\footnotetext{
${ }^{8}$ The Vietnam GsT is available for download at www.nrel.gov/international/geospatial_toolkits.html.
} 


\section{Wind Energy Potential and Opportunities in Quảng Bình Province}

The north-central coastal province of Quảng Bình is home to some of Vietnam's best wind resources. Over $90 \%$ of the province's land area is characterized by wind Class 3 or better (i.e., annual mean wind speeds over 6.4 meter per second $[\mathrm{m} / \mathrm{s}]$ at a $65-$ meter [m] hub height), which is considered an informal threshold for utility-scale wind potential in the United States [17]. The total theoretical wind potential in Quảng Bình is approximately 36.8
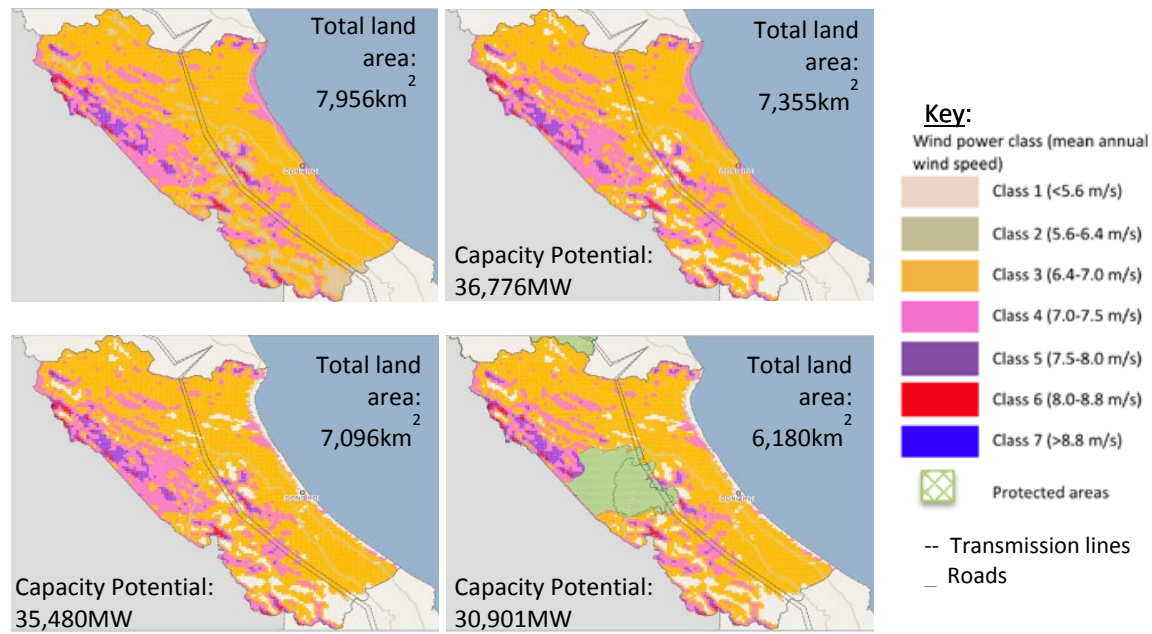

Figure B-2. Wind maps of Quảng Bình province, indicating total land area and wind capacity potential under different scenarios. Top left: total wind potential for entire province. Top right: high-quality wind resource (Class 3 or above). Bottom left: high-quality resource, excluding water bodies and urban areas. Bottom right: high-quality resource, excluding water bodies, urban areas, and protected areas.

gigawatts (GW). Filtering out small urban areas and water bodies fundamentally incompatible with wind energy development reduces technical potential to $35.5 \mathrm{GW}$. If this entire resource were developed, wind energy could supply $104,247 \mathrm{GWh} / \mathrm{yr}$, enough to meet $99.9 \%$ of Vietnam's domestic electricity demand [18]. Figure B-2 illustrates the screening of wind resource potential according to resource class and land use, as well as the impact of filtering the wind resource over the 900 square kilometers $\left(\mathrm{km}^{2}\right)$ Phong Nha-Kẻ Bàng National Park, a protected World Heritage site in which development is likely to be restricted.

Developing utility-scale wind on steep land may not be economical due to the high costs associated with grading. Quảng Bình's economic wind resource potential is highly sensitive to slope: filtering areas with slopes over $5 \%$ halves the technical capacity potential, as shown in Figure B-3. Moreover, approximately 85\% of Quảng Bình's strongest wind resources (Class 5 or better) occur over steep lands. While developing utility-scale wind power facilities on this land may not be cost-effective, provincial or national planning that encourages off-grid wind development might take advantage of these excellent resources. Distributed applications could also be designed to support development objectives; for instance, the northwest district of Minh Hóa has strong mountain wind resources but is characterized by low electrification and high poverty rates (30\% and $73 \%$, respectively, as shown in Figure B-3). Other districts, such as Lê Thủy, Quảng Trạch, Quảng Ninh, and Bố Trạch, have been designated as "extremely miserable" areas [19]. Targeting off-grid wind development in these areas could improve electrification and enhance livelihoods. 

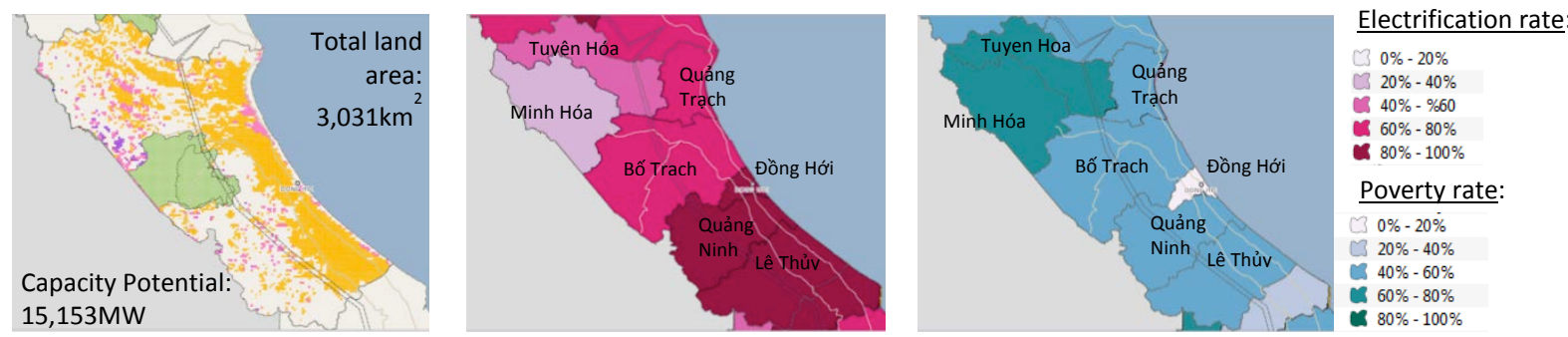

Figure B-3. Left to right: wind resource, excluding areas having a slope greater than $5 \%$; districtlevel electrification rate; district-level poverty rate

Proximity to transmission and transportation infrastructure also influences the economics of wind projects, as the significant costs of extending infrastructure are often born by the development community. Figure B-4 shows the wind resource available within $10 \mathrm{~km}$ of existing road and transmission networks. Based on these screens, out of Quảng Bình's $35.5 \mathrm{GW}$ of technical wind potential, only $2.9 \mathrm{GW}$ may be economical for utility-scale development (i.e., on low-slope lands within $10 \mathrm{~km}$ of both major roads and transmission networks). ${ }^{9}$
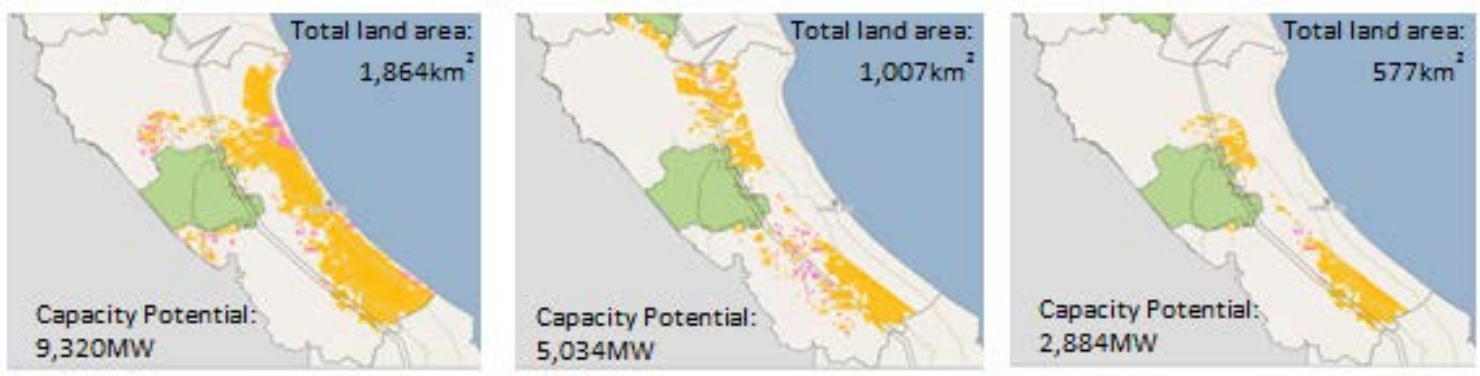

Figure B-4. Wind resource sensitivity to road and transmission access. From left to right: highquality wind resource available within $10 \mathrm{~km}$ of 1) roads, 2) transmission lines, and 3) roads and transmission lines. Excludes land uses described above.

As shown in Figure B-4, almost none of the province's $380 \mathrm{~km}^{2}$ over which wind power densities exceed $7.5 \mathrm{~m} / \mathrm{s}$ (Class 5 at $65 \mathrm{~m}$ ) are within $10 \mathrm{~km}$ of roads and transmission. Higher wind power densities are associated with higher capacity factors and therefore lower project costs. An illustrative calculation indicates the simplified levelized cost of electricity (LCOE) for utility-scale wind development in areas of Vietnam with Class 3 resources (mean annual wind speed of $6.4-7.0 \mathrm{~m} / \mathrm{s}$ ) is approximately USD $0.078 / \mathrm{kWh}$, whereas the LCOE in regions with resources at or above Class 5 is USD $0.062 / \mathrm{kWh}$ or less. ${ }^{10}$ Thus, enabling access to areas with high wind power densities can help encourage cost-effective wind deployment.

Based on these considerations, illustrative policy planning elements that might encourage wind development in Quảng Bình province include the following:

\footnotetext{
${ }^{9}$ If the wind resource is further screened to available wind within $2 \mathrm{~km}$ of both roads and transmission, technical potential drops to 68 megawatts.

${ }^{10}$ Calculation assumes utility-scale turbines with a capital cost of USD 1,700/kilowatt, operation and maintenance cost of USD 23.7/kilowatt-year, project life of 20 years, and discount rate of 10\% [4]. Capacity factors for various wind densities are described in [1]; simplified levelized cost of energy calculation methodology is described at www.nrel.gov/analysis/tech_lcoe_documentation.html.
} 
- Near-term utility-scale wind development that prioritizes projects in the areas near existing road and transmission infrastructure.

- Distributed household or microgrid-level wind generation that utilizes strong wind resources in steep, rural areas. Distributed generation could be particularly targeted at areas where wind development supports electrification, poverty reduction, and other local development goals.

- Integrated long-term transportation and transmission infrastructure planning that improves economic wind potential in the province by extending infrastructure to provide access to higher-quality wind resources that are currently remote.

\section{Wind Energy Potential in Bạc Liêu Province}

Bạc Liêu, a small province in the Mekong Delta region, is characterized by a moderate wind resource (Class 3 ) throughout its southern coastal region. The total theoretical wind capacity potential for this area is approximately $5.8 \mathrm{GW}$. Filtering the relatively small areas of land fundamentally incompatible with wind development (which includes the Vĩnh Lợi urban area and water bodies along the coastline) reduces technical wind potential to approximately $5.5 \mathrm{GW}$. Figure B-5 displays the spatial distribution of wind resources in Bạc Liêu.
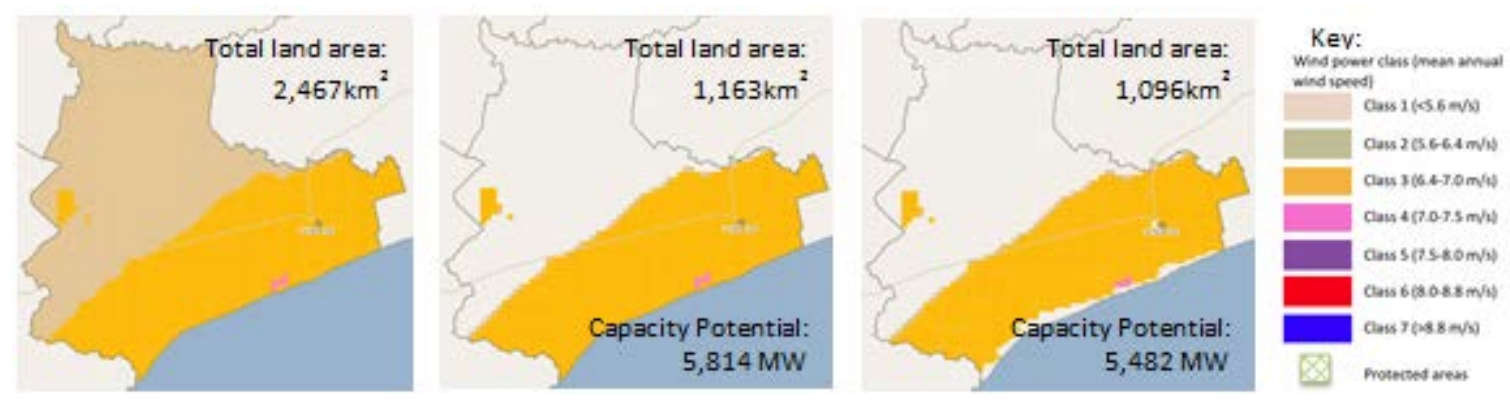

Figure B-5. Wind map of Bạc Liêu province, indicating total land area and wind capacity potential under different scenarios. From left to right: total wind potential for the entire province, highquality wind resource (Class 3 or better), and high-quality resource, excluding water bodies and urban areas.

Bạc Liêu's wind resource is not limited by any major protected areas or steep slopes (over 5\%). As shown in Figure B-6, the vast majority (78\%) of Bạc Liêu's high-quality wind resource occurs on croplands, followed by grass and shrub lands $(10 \%)$ and barren lands $(6 \%)$. From a technical and economic perspective, these types of land covers are compatible with wind development. However, local policies, programs, and awareness-building that encourage (or discourage) the use of wind energy on agricultural lands will have a major impact on the exploitation of these considerable wind resources in Bạc Liêu. 

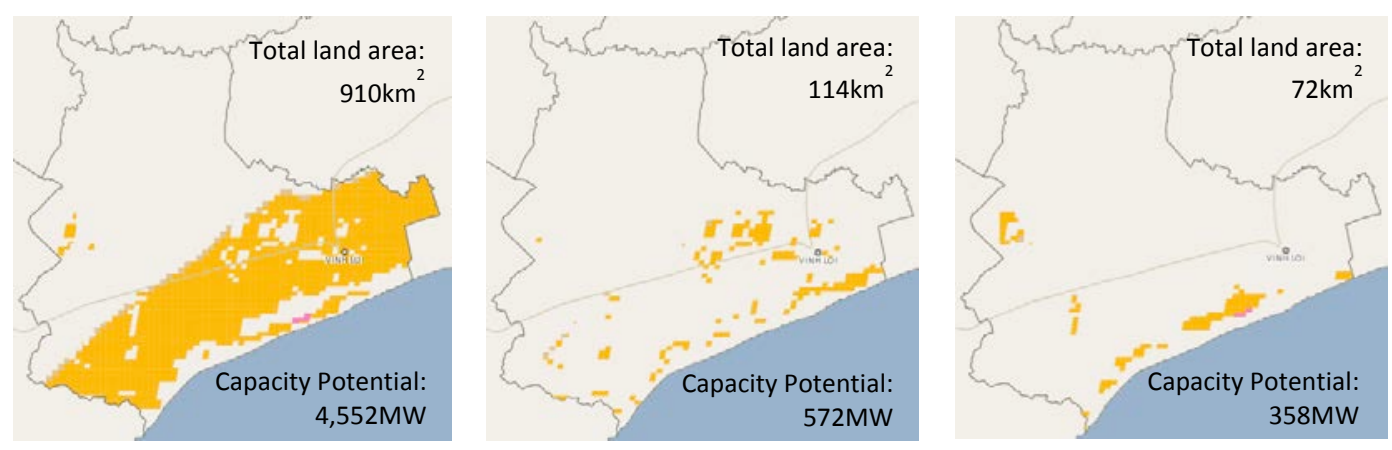

Figure B-6. Wind resource sensitivity to land use. From left to right: high-quality wind resource on croplands, grasslands and shrub lands, and barren lands.

The accessibility of Bạc Liêu's wind resource appears to be limited by infrastructure. According to the data available, no major transmission networks pass through Bạc Liêu, and only one major roadway (Highway 1A) crosses the province. As shown in Figure B7 , significant wind resource ( 830 megawatts [MW]) is available within $2 \mathrm{~km}$ of Highway $1 \mathrm{~A}$; extending road networks to $5 \mathrm{~km}$ and $10 \mathrm{~km}$ beyond this highway could facilitate access to an additional $1,235 \mathrm{MW}$ and $3,235 \mathrm{MW}$ of potential wind capacity, respectively.
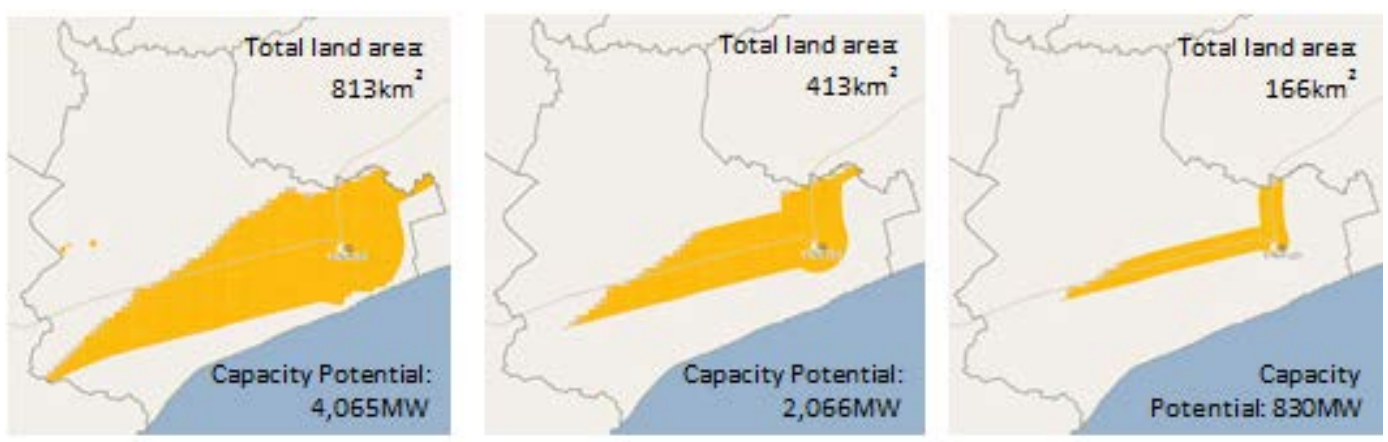

Figure B-7. Wind resource sensitivity to road access. From left to right: high-quality wind resource available within $10 \mathrm{~km}, 5 \mathrm{~km}$, and $2 \mathrm{~km}$, respectively, of major roads.

District-level electrification rates in Bạc Liêu are relatively low (ranging from 17\% in the Hồng Dân district to $28 \%$ in Vĩnh Lợi and Giá Rai; electrification reaches $73 \%$ in the capital Bạc Liêu district); and poverty rates range from $24 \%$ in Bạc Liêu to $40 \%$ in Vĩnh Lợi (see Figure B8). Bạc Liêu has developed, and the Prime Minister has
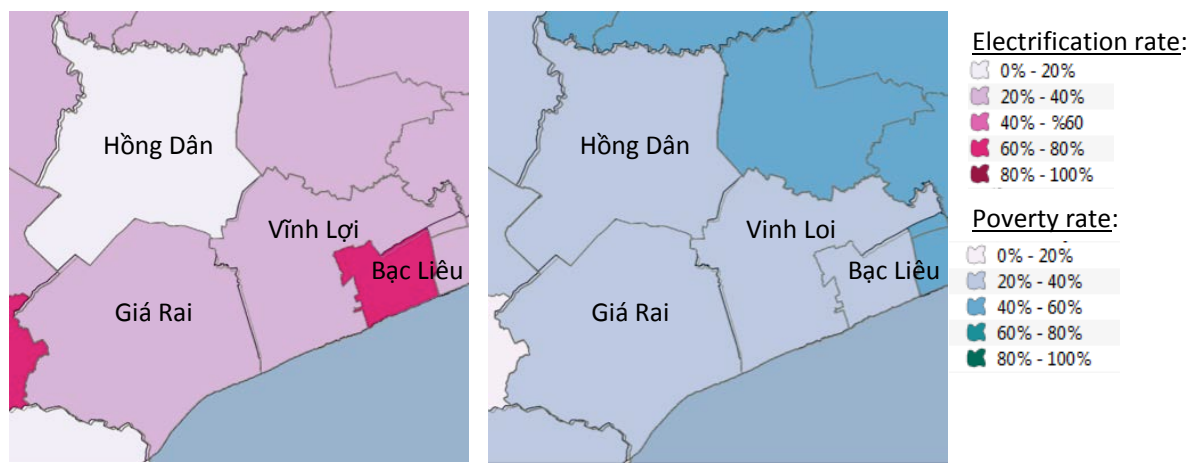

Figure B-8. District-level electrification (left) and poverty (right) rates approved, a provinciallevel socioeconomic development plan through 2020. This plan outlines numerous objectives compatible with wind energy, including developing high-tech agriculture, 
forestry, and fisheries industries and supporting infrastructure; developing a modern infrastructure system (including road and water transportation and electricity networks); reducing poverty, increasing access to education and health services; increasing jobs and trained workforce; and encouraging sustainable exploitation of natural resources [21].

Based on these considerations, illustrative planning elements that might encourage wind development in Bạc Liêu province include the following:

- Near-term off-grid wind applications, particularly those that support the agricultural community (e.g., wind energy for water pumping, hybrid biomasswind systems).

- Policies favoring the development of wind power on crop lands.

- Inclusion of wind energy corridors in forthcoming transportation and infrastructure planning efforts, including the identification of areas on the coastal side of the province where these future networks might support utilityscale wind generation to power new economic zones and high-tech agriculture, forestry, and fishery industrial facilities.

- Provincial vocational programs that incorporate training on wind energy installation, operation, and maintenance. 


\section{Appendix C:Vietnam Wind Analysis Annotated Bibliography}

Title: Multi-national Case Study of the Financial Cost of Wind Energy

Report Focus: Financing

Citation: Schwabe, P.; Lensink, S.; Hand, M. IEA Wind Task 26 - Multi-national Case Study of the Financial Cost of Wind Energy; Work Package 1 Final Report. NREL/TP6A20-48155. Golden, CO: National Renewable Energy Laboratory, 2011. www.nrel.gov/docs/fy110sti/48155.pdf

Summary: This report consists of two principal components. First, an overview and cross-country comparative analysis of the cost of wind energy is presented. The report then proceeds with a series of country-specific case studies that describe the unique cost elements of a typical wind energy facility in each of the represented countries. This report summarizes two perspectives and approaches: a high-level scenario planning approach and a sophisticated financial cash flow analysis approach. The majority of the analysis in this report, however, focuses on the financial cash flow analysis approach; thus, it represents the perspective of a private investor in a wind energy project in each of the participating countries.

Results of the analysis indicate the unsubsidized levelized cost of energy (LCOE) varies considerably among the countries represented in this study. The magnitude of the unsubsidized LCOE variation has been attributed to differences in country-specific energy production, investment cost, operations cost, and financing cost. As expected, the largest LCOE impact from country to country was the anticipated energy production component that could be due to the inherent wind regime, site selection, wind turbine design, or other factors. Market forces, such as electricity market structuring or the perception of risk in a wind project investment, also impacted the LCOE through large variations in both capital expenditures and financing costs. Costs attributed to the operations of a wind project ranged broadly across countries and had a sizable LCOE impact as well, though caution with the reported data for operation and maintenance costs were common. The unique factors contributing to the variations in LCOE across countries are explored further in the comparative analysis and country-specific wind energy chapters of the report.

Title: Land Use Requirements of Modern Wind Power Plants in the United States

Report Focus: Land use

Citation: Denholm, P.; Hand, M.; Jackson, M.; Ong, S. Land Use Requirements of Modern Wind Power Plants in the United States. NREL/TP-6A2-45834. Golden, CO: National Renewable Energy Laboratory, 2009. www.nrel.gov/docs/fy09osti/45834.pdf

Summary: This report provides data and analysis of the land use associated with modern, large wind power plants (defined as greater than 20 megawatts [MW] and constructed after 2000). The analysis discusses standard land-use metrics as established in the life cycle assessment literature, and then discusses their applicability 
to wind power plants. The report identifies two major 'classes' of wind plant land use: 1) direct impact (i.e., disturbed land due to physical infrastructure development) and 2) total area (i.e., land associated with the complete wind plant project). The analysis also provides data for each of these classes, derived from project applications, environmental impact statements, and other sources. It attempts to identify relationships among land use, wind plant configuration, and geography. The analysts evaluated 172 existing or proposed projects, which represent more than 26 gigawatts (GW) of capacity. In addition to providing land-use data and summary statistics, they identify several limitations to the existing wind project area data sets, and suggest additional analysis that could aid in evaluating actual land use and impacts associated with deployment of wind energy.

Title: Innovations in Wind and Solar PV Financing

\section{Report Focus: Financing}

Citation: Cory, K.; Coughlin, J.; Jenkin, T.; Pater, J.; Swezey, B. Innovations in Wind and Solar PV Financing. NREL/TP-670-42919. Golden, CO: National Renewable Energy Laboratory, 2008. www.nrel.gov/docs/fy08osti/42919.pdf

Summary: This study surveys some of the current issues related to wind and solar photovoltaic (PV) energy project financing in the electric power industry, and identifies both barriers to and opportunities for increased investment. Interviews were conducted with more than 30 wind and solar PV project developers, brokers, suppliers, and financiers to identify innovations that are moving beyond the traditional utility power purchase agreements (PPAs). Information from the interviews was compiled to create a concise synthesis of ideas and information on existing and evolving financial mechanisms relevant to the wind and solar PV energy industries. These include the different roles played by market participants, various ownership structures, available sources of financing, and how these elements may vary by technology and application. Several specific financing innovations for wind and solar PV projects were identified, including:

- Utilities are deciding to own wind, rather than just sign PPAs

- Power from solar PV projects is being sold directly to end users on a retail basis, through the third-party ownership model

- The financial sector is increasingly recognizing wind and solar PV as commercial, reliable technologies

- Merchant wind projects, without contracts covering their full output, are becoming a more attractive alternative

- Derivatives are being used to partially mitigate risk, adding to the potential appeal of merchant wind

- Renewable energy certificate (REC) revenues are increasingly important to the success of many projects

- Solar REC revenues in states with a solar renewable portfolio standard (RPS) set-aside are particularly important for solar PV development 
- As developers are acquired or team up with larger, better-capitalized companies, the financial options available to finance new renewable projects will increase

- Investors diversify wind and solar PV investment in a number of ways, including the purchase of structured debt instruments, entering into equity investment partnerships, and possibly partnering with hedge funds.

Title: WB/GEF Renewable Energy Development Project: Renewable Energy in China. NREL International Programs

Report Focus: PV and wind projects in China

Citation: WB/GEF Renewable Energy Development Project: Renewable Energy in China. NREL/FS-710-33067. Golden, CO: National Renewable Energy Laboratory, 2004. www.nrel.gov/docs/fy04osti/33067.pdf

Summary: This fact sheet briefly describes projects, financial assistance (grants, loans), and World Bank support in the form of project management.

Title: Renewable Energy Policy in China: Financial Incentives

Report Focus: Financing

Citation: Renewable Energy Policy in China: Financial Incentives; Renewable Energy in China. NREL/FS-710-36045. Golden, CO: National Renewable Energy Laboratory, 2004. www.nrel.gov/docs/fy04osti/36045.pdf

Summary: This fact sheet describes renewable energy financial incentives in China. "The major financial incentives in existence today include subsidies, tax-related incentives, custom duties, and pricing incentives, and the government is moving toward more comprehensive quantity- and price-based support mechanisms."

Title: Renewable Energy Policy in China: Overview

Report Focus: Policy

Citation: Renewable Energy Policy in China: Overview; Renewable Energy in China. NREL/FS-710-35786. Golden, CO: National Renewable Energy Laboratory, 2004. www.nrel.gov/docs/fy04osti/35786.pdf

Summary: This fact sheet describes renewable energy policies in China. "Similar to the way renewable policies are set in the United States, China's central government establishes the first two levels of policy. Local governments, including provincial, municipal, and county governments, establish the third level of policy with overall direction from the central government."

Title: Data Collection for Current U.S. Wind Energy Projects: Component Costs, Financing, Operations, and Maintenance

Report Focus: Financing 
Citation: Martin-Tretton, M.; Reha, M.; Drunsic, M.; Keim, M. Data Collection for Current U.S. Wind Energy Projects: Component Costs, Financing, Operations, and Maintenance; January 2011 - September 2011. NREL/SR-5000-52707. Golden, CO: National Renewable Energy Laboratory, 2012. www.nrel.gov/docs/fy12osti/52707.pdf

Summary: The majority of the report may not pertain to the paper, but the last section titled "Project Financing" (page 17) may be useful, as it "provides a high-level description of representative financing structures in 2010 and 2011 and relevant metrics for utility-scale wind power projects. Included is a qualitative outline of general wind development market conditions, including financing structures, capital availability, sources of funds (debt versus equity), and other information."

Title: Wind Energy Guide for County Commissioners

Report Focus: Wind overview (development process, environmental benefits, economic benefits, siting issues, public outreach, tax incentives, power system impacts, case studies)

Citation: Costanti, M. Wind Energy Guide for County Commissioners. NREL/SR-50040403; DOE/GO-102006-2370. Golden, CO: National Renewable Energy Laboratory, 2006. www.windpoweringamerica.gov/pdfs/wpa/county commissioners.pdf

Summary: This project is designed to provide county commissioners, planners, and other local county government officials with a practical overview of information required to successfully implement commercial wind energy projects in their county. The guidebook provides readers with information on the following 13 topics: Brief Wind Energy Overview; Environmental Benefits; Wind Energy Myths and Facts; Economic Development Benefits; Wind Economics; The Development Process; Public Outreach; Siting Issues; Property Tax Incentives; Power System Impacts; Permitting, Zoning, and Siting Processes; Case Studies; and Further Information. For each of the above topics, the guidebook provides an introduction that identifies the topic, why local government should care, a topic snapshot, how the topic will arise, and a list of resources that define and assess the topic.

Title: Developing Renewable Energy Projects Larger Than $10 \mathrm{MWs}$ at Federal Facilities

Report Focus: Project Development (applicable to non-government projects as well)

Citation: Developing Renewable Energy Projects Larger Than $10 \mathrm{MWs}$ at Federal Facilities. Large-Scale Renewable Energy Guide, Federal Energy Management Program (FEMP). NREL/BK-7A40-52121; DOE/GO-102013-3915. Golden, CO: National Renewable Energy Laboratory, 2013. www1.eere.energy.gov/femp/pdfs/largescalereguide.pdf

Summary: Because the vast majority of the investment that is required to meet the goals for large-scale renewable energy projects will come from the private sector, this guide has been organized to match federal processes with typical phases of commercial project development. The main purpose of this guide is to provide a project development framework to allow the federal government, private developers, and investors to 
work in a coordinated fashion on large-scale renewable energy projects. The framework includes key elements that describe a successful, financially attractive large-scale renewable energy project.

Title: Understanding Renewable Energy Businesses: Aligning Renewable Energy Firms and Economic Developers

Report Focus: Wind industry development

Citation: Thornstensen, L.; Chen, J.; Brown, E. Understanding Renewable Energy Businesses: Aligning Renewable Energy Firms and Economic Developers. International Economic Development Council, 2013.

www.iedconline.org/clientuploads/Downloads/edrp/IEDC Renewable Energy Business es.pdf

Summary: The section "Wind Industry Survey Results" (page 26) may be useful. It covers policy tools, challenges to growth, and economic development programs.

Key findings:

- Most important state or local assets are policies, incentives, and regulatory climate

- Most effective policy tools are financial incentives for renewable energy production

- The leading challenge for firms is federal policy and regulatory uncertainty

- The most impactful economic development program, as with solar, is a formalized strategic plan for growing renewable energy at the state level.

Title: Policies and market factors driving wind power development in the United States

Report Focus: Policy and market incentives

Citation: Bird, L.; Bolinger, M.; Gagliano, T.; Wiser, R.; Brown, M.; Parsons, B. "Policies and Market Factors Driving Wind Power Development in the United States." Energy Policy, (33), 2005; pp. 1397-1407. http://dx.doi.org/10.1016/j.enpol.2003.12.018

Summary: This paper explores the key factors at play in the 12 states in which a substantial amount of wind energy capacity has been developed or planned. Some of the factors that are examined include policy drivers (such as renewable portfolio standards, federal and state financial incentives) and market drivers (such as consumer demand for green power, natural gas price volatility, and wholesale market rules).

Title: Fostering a renewable energy technology industry: An international comparison of wind industry policy support mechanisms

Report Focus: Wind industry development 
Citation: Lewis, J.; Wiser, R. Fostering a renewable energy technology industry: An international comparison of wind industry policy support mechanisms. Berkeley, CA: Ernest Orlando Lawrence Berkeley National Laboratory, 2005. http://dx.doi.org/10.1016/j.enpol.2006.06.005

Summary: This article examines the importance of national and sub-national policies in supporting the development of successful global wind turbine manufacturing companies. We explore the motivations behind establishing a local wind power industry, and the paths that different countries have taken to develop indigenous large wind turbine manufacturing industries within their borders. This is done through a crosscountry comparison of the policy support mechanisms that have been employed to directly and indirectly promote wind technology manufacturing in twelve countries. We find that in many instances there is a clear relationship between a manufacturer's success in its home country market and its eventual success in the global wind power market. Whether new wind turbine manufacturing entrants are able to succeed will likely depend in part on the utilization of their turbines in their own domestic market, which in turn will be influenced by the annual size and stability of that market. Consequently, policies that support a sizable, stable market for wind power, in conjunction with policies that specifically provide incentives for wind power technology to be manufactured locally, are most likely to result in the establishment of an internationally competitive wind industry.

Title: A Framework for Project Development in the Renewable Energy Sector

Report Focus: Project development (risk reduction)

Citation: Springer, R. Framework for Project Development in the Renewable Energy Sector. NREL/TP-7A40-57963. Golden, CO: National Renewable Energy Laboratory, 2013. http://www.nrel.gov/docs/fy13osti/57963.pdf

Summary: The concepts, descriptions, diagrams, and acronyms developed and described herein are meant to provide a contextual framework, as well as a systematic, repeatable process to assist a potential project sponsor in understanding and navigating early-stage project development. Professional project developers will recognize these concepts and hold them as intuitive and even obvious, though the fundamentals of this specialized field are rarely written down and defined as they are here.

Title: China: Meeting the Challenges of Offshore and Large-Scale Wind Power: Strategic Guidance

Report Focus: Project development and implementation

Citation: China - Meeting the Challenges of Offshore and Large-Scale Wind Power: Strategic Guidance. Washington, DC: The World Bank, 2010. https://openknowledge.worldbank.org/bitstream/handle/10986/2861/547460ESWOP113 10Strategic0Guidance0.pdf?sequence $=1$ 
Summary: This publication comprises three reports:

- Strategic Messages for Offshore and Large-Scale Wind Power (project development and support)

- Implementation Guidance for Offshore and Large-Scale Onshore Wind Power Development in China (detailed recommendations for offshore, intertidal, and large-scale onshore wind power development and addressing the issue of reliable wind power and ability of the grid to transmit and distribute power)

- Technical Notes on Resource Assessment, Construction, and Grid Integration

Title: Wind Power Development: Economics and Policies

Report Focus: Project development (and status of wind installations, costs, and integration)

Citation: van Kooten, G. Cornelis; Timilsina, Govinda R. Wind Power Development: Economics and Policies. Washington, DC: The World Bank, Development Research Group, Environment and Energy Team, 2009.

https://openknowledge.worldbank.org/bitstream/handle/10986/4063/WPS4868.pdf?sequ ence $=1$

Summary: This study reviews the prospects of wind power at the global level. Wind power faces a large number of technical, economic, financial, institutional, market, and other barriers. To overcome these barriers, many countries have employed various policy instruments, including capital subsidies, tax incentives, tradable energy certificates, feed-in tariffs, grid access guarantees, and mandatory standards. Besides these policies, climate change mitigation initiatives resulting from the Kyoto Protocol (e.g., carbon dioxide-emission reduction targets in developed countries and the Clean Development Mechanism in developing countries) have played a significant role in promoting wind power.

Title: Design and Performance of Policy Instruments to Promote the Development of Renewable Energy: Emerging Experience in Selected Developing Countries

Report Focus: Policy, financial incentives, market facilitation

Citation: Azuela, G.E.; Barroso, L.A. Design and Performance of Policy Instruments to Promote the Development of Renewable Energy: Emerging Experience in Selected Developing Countries. Washington, DC: The World Bank, 2012. https://openknowledge.worldbank.org/bitstream/handle/10986/9379/709090PUB0EPI00 67869B09780821396025.pdf?sequence $=1$

Summary: This report summarizes the results of a recent review of the emerging experience with the design and implementation of policy instruments to promote the development of renewable energy ( $R E$ ) in a sample of six representative developing countries and transition economies. The review focused mainly on price- and quantitysetting policies, but it also covered fiscal and financial incentives, as well as relevant market facilitation measures. The lessons learned were taken from the rapidly growing 
literature and reports that analyze and discuss RE policy instruments in the context of different types of power market structures. The analysis considered all types of gridconnected RE options except large hydropower: wind (onshore and offshore), solar (photovoltaic and concentrated solar power), small hydropower (with capacities below 30 megawatts), biomass, bioelectricity (cogeneration), landfill gas, and geothermal. The six countries selected for the review included Brazil, India, Indonesia, Nicaragua, Sri Lanka, and Turkey.

Title: Greening the Wind: Environmental and Social Considerations for Wind Power Development

Report Focus: Wind environmental and social issues

Citation: Ledec, George C.; Rapp, Kennan W.; Aiello, Roberto G. Greening the Wind: Environmental and Social Considerations for Wind Power Development. Washington, DC: The World Bank, 2011. https://openknowledge.worldbank.org/handle/10986/2388

Summary: This report identifies good practices for managing the key environmental and social issues associated with wind power development and provides advice on how best to address these issues in project planning, construction, and operation and maintenance. It provides detailed background information on wind power, with special focus on two emerging themes of growing scientific and public interest: namely the biodiversity-related impacts and the broader socioeconomic and cultural dimensions of wind power development. Like wind power itself, the scope of this report is worldwide, although special attention is paid to the issues characteristic of the Latin America and Caribbean region. While the principal focus is on land-based wind power, it also briefly addresses the environmental and social impacts related to offshore wind development. Wind power today is widely regarded as a key component of an environmentally sustainable, low-carbon energy future because it is renewable, requires almost no water, and generates near-zero emissions of greenhouse gases and other pollutants. In many parts of the world, wind power has the potential to significantly reduce greenhouse gas emissions from electric power generation, thereby helping to limit the severe environmental and social consequences of human-induced climate change. The growth of wind power has also occurred due to its other positive attributes, including growing economic competitiveness. The adverse biodiversity-related impacts of wind power facilities mainly involve birds, bats, and natural habitats.

Title: Integrating Renewable Energy into the Transmission and Distribution System of the U.S. Virgin Islands

Report Focus: Case study

Citation: Burman, K.; Olis, D.; Gevorgian, V.; Warren, A.; Butt, R.; Lilienthal, P.; Glassmire, J. Integrating Renewable Energy into the Transmission and Distribution System of the U. S. Virgin Islands. NREL/TP-7A20-51294. Golden, CO: National Renewable Energy Laboratory, 2011. http://www.nrel.gov/docs/fy110sti/51294.pdf

Summary: This report focuses on the economic and technical feasibility of integrating renewable energy technologies into the U.S. Virgin Islands transmission and distribution 
systems. The report includes three main areas of analysis: 1) the economics of deploying utility-scale renewable energy technologies on St. Thomas/St. John and St. Croix; 2) potential sites for installing roof- and ground-mounted photovoltaic systems and wind turbines and the impact renewable generation will have on the electrical subtransmission and distribution infrastructure, and 3) the feasibility of a 100- to 200megawatt power interconnection of the Puerto Rico Electric Power Authority, Virgin Islands Water and Power Authority, and British Virgin Islands grids via a submarine cable system.

Title: Initial Economic Analysis of Utility-Scale Wind Integration in Hawaii

Report Focus: Case study

Citation: Springer, R. Initial Economic Analysis of Utility-Scale Wind Integration in Hawaii. NREL/TP-7A40-54248. Golden, CO: National Renewable Energy Laboratory, 2012. www.nrel.gov/docs/fy12osti/54248.pdf

Summary: This report summarizes an analysis, conducted by the National Renewable Energy Laboratory in May 2010, of the economic characteristics of a particular utilityscale wind configuration project that has been referred to as the 'Big Wind' project. The study was designed to characterize the economics of the project and gain a perspective of its feasibility, given available technical and cost information. The primary question we sought to answer was: How much revenue would such a project likely require to be successful, and how does that cost relate to the relative energy economics in Hawaii?

Title: Community Wind Development Handbook

Report Focus: Wind development

Citation: Community Wind Development Handbook. Developed on behalf of Rural Minnesota Energy Board, undated. www.auri.org/wpcontent/assets/legacy/research/Community\%20Wind\%20Handbook.pdf

Summary: The Community Wind Development Handbook is designed to give developers of "wholesale" community wind projects practical knowledge of what to expect when developing commercial-scale community wind energy projects in the range of 2 to 50 megawatts. These wind projects are designed for bulk power generation for sale to a utility company or large electricity user and can supply enough energy to serve several hundred to thousands of homes. Typically, planning and developing a wholesale community wind project takes several years, working with a dedicated team of professionals that have expertise in business and finance, easements, power purchase agreements, engineering, construction and project management, and experience in the utility sector, as well as other aspects of the wind industry. The handbook provides insight into every aspect of the community wind development process and helpful information about managing a project from the beginning of the development process through decommissioning. It includes a primer on wind resource assessment based on current technology and industry standards, and information about financing, business structures, tax incentives and liability, the interconnection of your project and acquiring a power purchase agreement, and selecting and purchasing turbines and associated 
equipment. It is intended to provide prospective developers with tools for each these steps, cost estimates, and guidance on when and where to involve outside expertise. Developed and reviewed by a broad team of wind, legal, engineering, and financial experts, Windustry's Community Wind Handbook includes:

- A new pro forma model tool

- Annotated examples of various legal agreements

- Detailed review of policy incentives

- New case studies.

Title: Removing Subsidies: Leveling the Playing Field for Renewable Energy Technologies.

Report Focus: Market policies (specifically subsidies)

Citation: Pershing, J; Mackenzie, J. Removing Subsidies: Leveling the Playing Field for Renewable Energy Technologies. Renewable Energy Policy Network for the $21^{\text {st }}$ Century, 2004. www.ren21.net/Portals/0/documents/irecs/renew2004/Removing\%20subsidies.pdf

Summary: By quantifying some of these subsidies, including their economic and environmental costs, the paper sets the stage for a series of recommendations on subsidy reform and its implications for renewable energy. Recommendations include:

- Creating targeted, sound incentives that are practical, transparent, predictable and promote market competition

- Aiming at all aspects of the system, including technical barriers, market impediments, administrative barriers and social and environmental constraints.

Title: Evaluation of Different Feed-In Tariff Design Options: Best Practice Paper for the International Feed-In Cooperation (3rd Edition)

Report Focus: Market incentives (feed-in tariffs)

Citation: Klein, A.; Pfluger, B.; Held, A.; Ragwitz, M.; Resch, G.; Faber, T. Fraunhofer Institute Systems and Innovation Research \& Energy Economics Group, 2010. https://financere.nrel.gov/finance/node/1537

Summary: This report is written with the goal to describe and analyze the feed-in tariff designs applied in the member states of the European Union. Designs to reduce the electricity generation costs, as well as the costs for society, are presented and investigated. The questions of distributing the costs of renewable energy sources (RES) support and how to improve the integration of RES into the electricity grid are covered. Best practice examples are analyzed and their consequences for RES generators and electricity consumers are described. 
Title: Developing an Effective State Clean Energy Program: Renewable Energy Incentives

Report Focus: Wind industry growth

Citation: Developing an Effective State Clean Energy Program: Renewable Energy Incentives. Clean Energy States Alliance, 2009.

www.cleanenergystates.org/assets/Uploads/Resources-pre-8-16/CESA-renewableenergy-incentives-mar09.pdf

Summary: This briefing paper summarizes innovative approaches and practices that have worked effectively for state clean energy programs in providing small renewable project incentives. For example, states should commit and release funding in a way that ensures long-term continuity of the program (e.g., five to 10 years), allowing local markets to develop and stabilize. States should also consider establishing a gradually declining level of rebates, zeroing out after 10 years.

Title: United Nations Environment Programme (UNEP) Handbook for Drafting Laws on Energy Efficiency and Renewable Energy Resources

Report Focus: Policy and laws for promoting renewable energy

Citation: United Nations Environment Programme (UNEP) Handbook for Drafting Laws on Energy Efficiency and Renewable Energy Resources. United Nations Environment Programme, 2007. www.unep.org/climatechange/mitigation/Portals/93/documents/EnergyEfficiency/UNEP Energy Handbook.pdf

Summary: The United Nations Environment Programme (UNEP) Handbook for Drafting Laws on Energy Efficiency and Renewable Energy Resources is written in response to needs expressed by developing country energy law draftsmen to UNEP for assistance in drafting legislative provisions for promotion of energy efficiency and renewable energy, and particularly their environmental dimensions. The handbook is designed to be a user-friendly guide rather than a technical compendium or comprehensive collection of relevant legislation. The focus is on national legislation, but encompasses national constitutional provisions, regulations, and state and local laws where they are the key determinants of the promotion of efficiency and renewable resources. Emphasis is placed on adaptation to local country needs and conditions. The handbook describes the key environmental and implementation issues associated with efficiency and renewable energy resources and presents legislative options from both developed and developing countries for dealing with them, including sample excerpts from legislation.

Title: Renewable Energy Markets in Developing Countries

Report Focus: Markets/policy

Citation: Martinot, E.; Chaurey, A.; Lew, D.; Moreira, J.R.; Wamukonya, N. "Renewable Energy Markets in Developing Countries." Annual Review Energy Environment (27), 
2002; pp. 309-348.

www.annualreviews.org/doi/pdf/10.1146/annurev.energy.27.122001.083444

Summary: In this paper we provide an aggregate review of past market experience, existing applications, and results of policies and programs, organized by end-use application rather than by technology. We then review the emerging lessons suggested by these experiences for six key issues ranging from rural development impacts to subsidies to enterprise development. We believe that grouping lessons by issue proves more useful than a single group of renewable energy lessons.

Title: Asia Energy Mixes from Socio-Economic and Environmental Perspectives

Report Focus: Energy overview in Association of Southeast Asian Nations countries

Citation: Thavasi, V.; Ramakrishna, S. "Asia Energy Mixes from Socio-Economic and Environmental Perspectives." Energy Policy (37:11), 2009; pp. 4240-4250. www.sciencedirect.com/science/article/pii/S0301421509003449

Summary: This report highlights the current energy scenario in these countries and their effort toward an affordable and sustainable clean energy future. The energy policy to enhance energy security and improve environmental sustainability is also explicated in this article.

Title: Strategies to overcome barriers for cleaner generation technologies in small developing power systems: Sri Lanka case study

Report Focus: Case study: Sri Lanka

Citation: Wijayatunga, P.D.C.; Siriwardena, K.; Fernando, W.J.L.S.; Shrestha, R.M.; Attalage, R.A. "Strategies to Overcome Barriers for cleaner Generation Technologies in Small Developing Power Systems: Sri Lanka Case Study." Energy Conversion and Management (47:9-10), 2006; pp. 1179-1191. http://ac.elscdn.com/S0196890405001834/1-s2.0-S0196890405001834-main.pdf? tid=f60bc8dc05e6-11e3-a621$\underline{00000 a a b 0 f 01 \& a c d n a t=13765977085528218965 e c b 383 c d a c 88 a 24 d 48 e 1 f 0}$

Summary: This paper presents the outcome of a study involved in identifying and ranking the barriers to the promotion of cleaner and energy efficient technologies and strategies to overcome these barriers in Sri Lanka. Barriers for renewable energy-based systems, such as wind and wood fuel-fired plants (dendro thermal power), and cleaner technologies, such as liquefied natural gas-fired combined cycle and integrated gasification combined cycle (coal), were identified based on a survey. A direct assessment multi-criteria decision-making method called Analytic Hierarchy Process (AHP) was used to rank the barriers. The most effective strategies are proposed to address the three major barriers for each of these technologies based on extensive discussions with all the stakeholders in the electricity industry.

It was found that lack of financing instruments, high initial cost, and lack of assurance of resource supply or availability are the main barriers for renewable technologies. As for 
cleaner fuel and technology options associated with conventional generation systems, the lack of a clear government policy, uncertainty of fuel supplies and their prices, and the reliability of the technologies themselves are the major barriers.

Strategies are identified to overcome the above barriers. Establishment of a proper feed-in tariff, geographical diversification of installations, and capacity building in commercial banks are suggested for wind power. Investment incentives, streamlining of wood production, and research on site identification are proposed for wood fuel-fired plants. Also, the study suggests delayed implementation, combined planning with other sectors of the economy, incorporating environmental cost in planning, and investment incentives as strategies for integrated gasification combined cycle and liquefied natural gas-based technologies.

Title: Impacts of wind power generation and $\mathrm{CO}_{2}$ emission constraints on the future choice of fuels and technologies in the power sector of Vietnam

Report Focus: Market

Citation: Nguyen, K.Q. "Impacts of Wind power Generation and $\mathrm{CO}_{2}$ Emission Constraints on the Future Choice of Fuels and Technologies in the Power Sector of Vietnam." Energy Policy (35:4), 2007; pp. 2305-2312. http://ac.elscdn.com/S0301421506003193/1-s2.0-S0301421506003193-main.pdf? tid=1b7e11d8$05 \mathrm{e} 7-11 \mathrm{e} 3-\mathrm{bdb} 5-$ 00000aab0f6c\&acdnat=1376597771 1857aaf4d9c330b2634cc86b5638ddf7

Summary: This paper examines the impacts of wind power generation on the future choice of fuels and technologies in the power sector of Vietnam. The study covers a time frame of 20 years from 2005 to 2025 , and the MARKAL model has been chosen to be adaptable to this specific task. The results of the study show that on a simple cost base, power generated from wind is not yet competitive with that of fossil fuel-based power plants. In order to make wind energy competitive, either carbon tax or an emission reduction target on the system must be imposed. The presence of wind power would affect not only the change in generation mix from coal-based power plants to wind turbines but also an increase in the capacity of other technologies, which emit less carbon dioxide. It thus helps reduce fossil fuel requirement and consequently enhances energy security for the country. The study also shows that wind turbine in Vietnam could be a potential Clean Development Mechanism project for annex I party countries.

Title: Wind energy in Vietnam: Resource assessment, development status and future implications

Report Focus: Resource potential and wind development status

Citation: Nguyen, K.Q. "Wind Energy in Vietnam: Resource Assessment, Development Status and Future Implications." Energy Policy (35:2), 2007; pp. 1405-1413. http://ac.els-cdn.com/S0301421506001893/1-s2.0-S0301421506001893main.pdf? tid=2f7ae42c-05e7-11e3-a62100000aab0f01\&acdnat=1376597804 b80470242ba7ca94a6b6e674ed78f9b1 
Summary: The aim of this study is to estimate the technical potential of wind energy in Vietnam and discuss strategies for promoting the market penetration of wind energy in the country. For the wind resource assessment, a geographical information systemassisted approach has been developed. It is found that Vietnam has a good potential for wind energy. About 31,000 square kilometers of land area can be available for wind development, in which 865 square kilometers equivalents to a wind power of 3,572 megawatts and has a generation cost of less than USD 6 cents/kilowatt-hour. The study also proves that wind energy could be a good solution for about 300,000 rural non-electrified households. While wind energy brings about ecological, economic, and social benefits, it is only modestly exploited in Vietnam, where the main barrier is the lack of political impetus and a proper framework for promoting renewable energy. The priority task therefore is to set a target for renewable energy development and to find instruments to achieve such a target. The main instruments proposed here are setting feed-in tariff and providing investment incentives.

Title: Economic potential of renewable energy in Vietnam's power sector

Report Focus: Renewable energy economic potential

Citation: Nguyen, N.T.; Minh, H. "Economic Potential of Renewable Energy in Vietnam's Power Sector." Energy Policy (37:5), 2009; pp. 1601-1613. http://ac.elscdn.com/S0301421508007635/1-s2.0-S0301421508007635-main. pdf? tid=479f9bf605e7-11e3-bdb5-

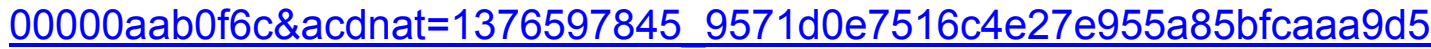

Summary: A bottom-up integrated resource planning model is used to examine the economic potential of renewable energy in Vietnam's power sector. In a baseline scenario without renewables, coal provides $44 \%$ of electricity generated from 2010 to 2030. The use of renewables could reduce that figure to $39 \%$, as well as decrease the sector's cumulative emission of carbon dioxide by $8 \%$, sulfur dioxide by $3 \%$, and nitrogen dioxide by $4 \%$. In addition, renewables could avoid installing 4.4 gigawatts in fossil fuel generating capacity, conserve domestic coal, and decrease coal and gases imports, improving energy independence and security. Wind could become costcompetitive, assuming high but plausible fossil fuel prices, if the cost of the technology falls to USD 900/kilowatt.

Title: ASEAN towards clean and sustainable energy: Potentials, utilization and barriers

Report Focus: Policy

Citation: Lidula, N.W.A.; Mithulananthan, N.; Ongsakul, W.; Widjaya, C.; Henson, R. "ASEAN towards Clean and Sustainable Energy: Potentials, Utilization and Barriers." Renewable Energy (32:9), 2007; pp. 1441-1452. http://ac.elscdn.com/S0960148106002217/1-s2.0-S0960148106002217- $\mathrm{main}$. pdf? tid=58de6eba05e7-11e3-b7e0$\underline{00000 a a b 0 f 6 c \& a c d n a t=13765978739733 \mathrm{ff} 6 \mathrm{fd} 15 \mathrm{~b} 348911 \mathrm{e} 6 \mathrm{aa} 62 \mathrm{eefe} 4 \mathrm{a} 5 \mathrm{~b}}$

Summary: This paper reports the outcome of the project on "Capacity building in formulating harmonized policy instruments for the promotion of Renewable Energy and 
Energy Efficiency in the ASEAN member countries." With the growing concerns about greenhouse gas emission and consequent climate change, renewable energy sources have become more attractive option for electricity generation around the world. Studies have been made on the status of renewable energy potential and utilization, major barriers in promoting renewable energy in Association of Southeast Asian Nations (ASEAN) countries, major energy policies to overcome barriers, and existing renewable energy and energy efficiency policies in ASEAN countries. The paper concludes ASEAN has not utilized its renewable energy resources anywhere near its potential. Analysis found the key factor that has to be amended is "policies and regulations in renewable energy and energy efficiency" at both country level and regional level. But, ASEAN is not yet ready for the full harmonization of the policies. However, it recommends that, with the project outputs, it is possible to focus on the specific policy instruments common to most of the member countries, such that it could use to augment ASEAN Plan of Action for Energy Cooperation (APAEC) initiatives. 


\section{Appendix D: Geospatial Toolkit National Screening}

\section{Data}

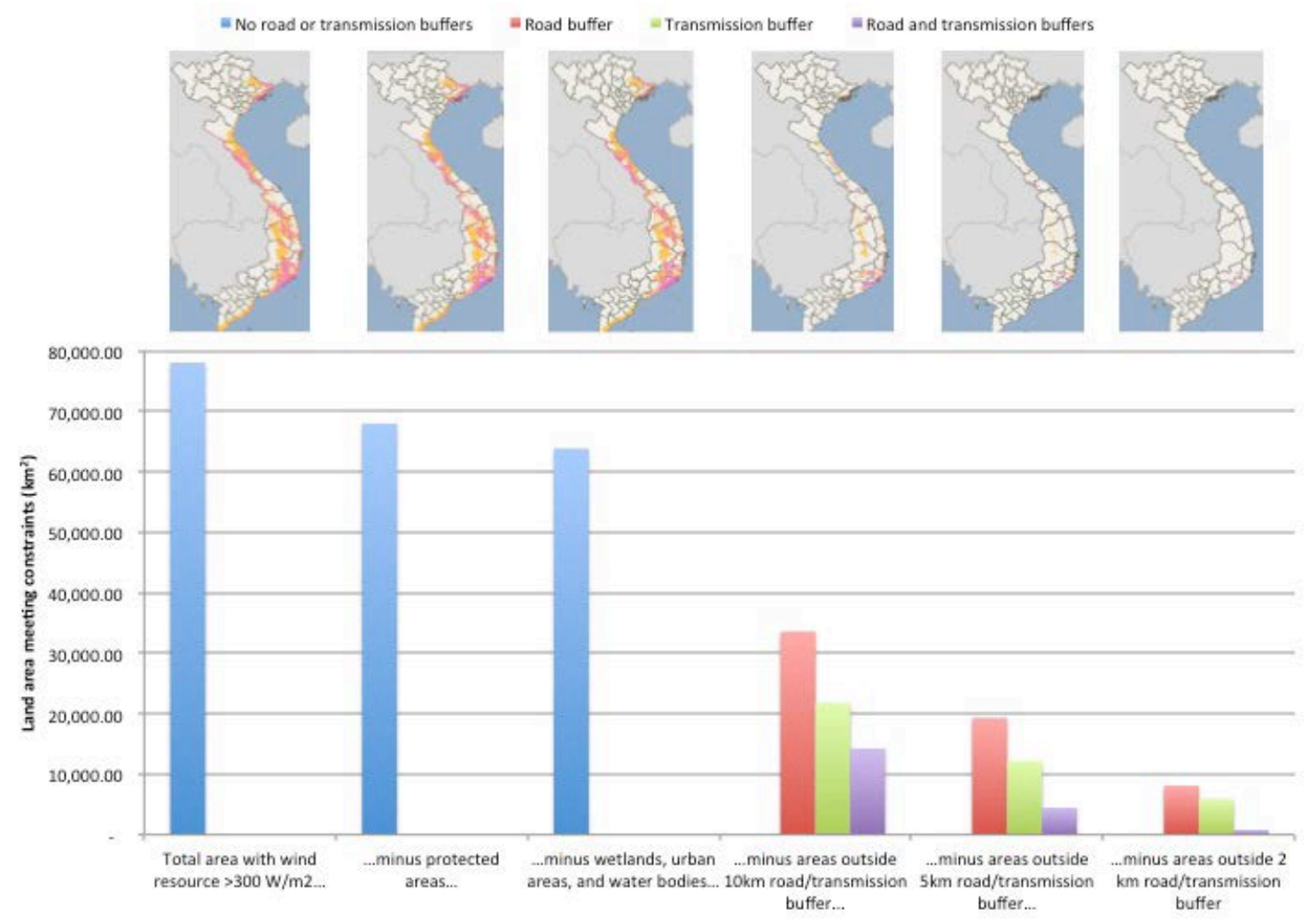

Figure D-1. Vietnam wind resource potential (land area): sensitivity analysis 


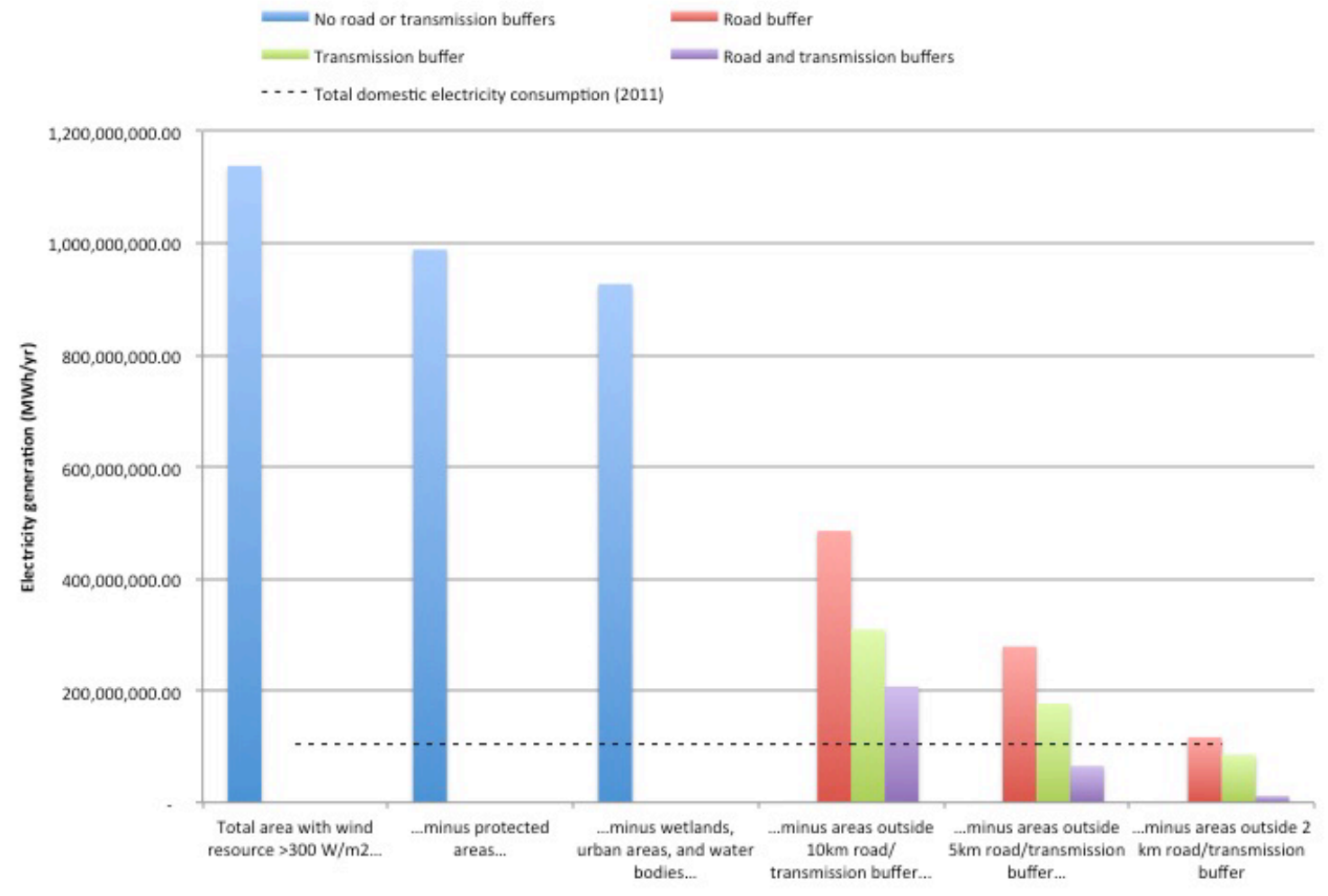

Figure D-2. Vietnam wind resource potential (generation potential): sensitivity analysis

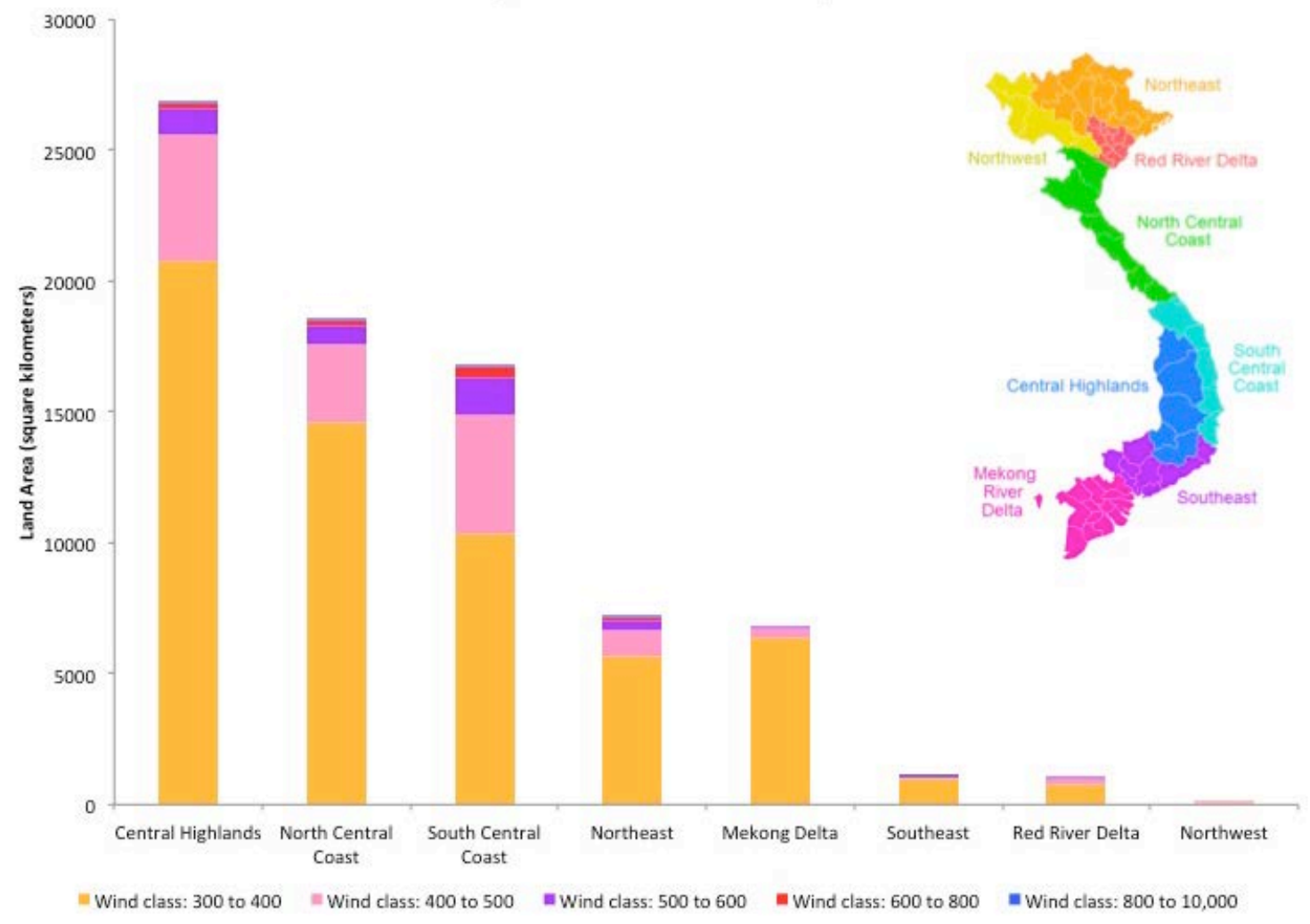

Figure D-3. Regional wind resource availability 


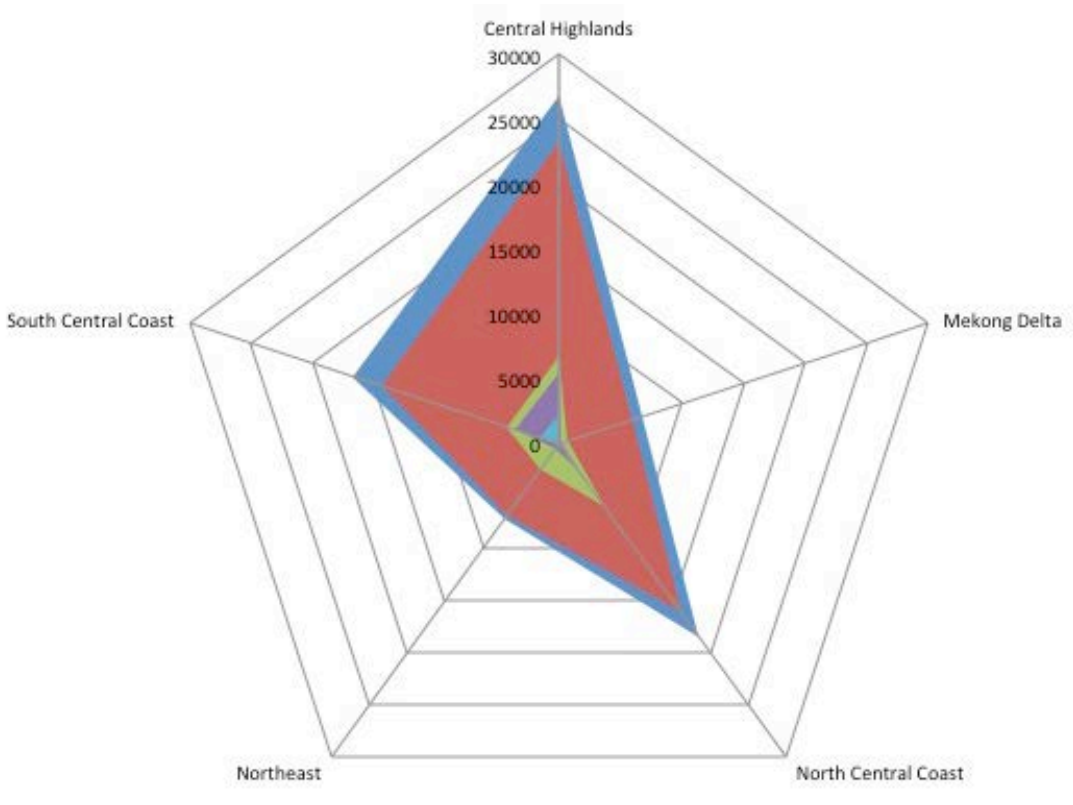

$=$ Wind resource $>300 \mathrm{~W} / \mathrm{m} 2$

Wind resource $>300 \mathrm{~W} / \mathrm{m} 2$; excludes protected areas
"Wind resource $>300 \mathrm{~W} / \mathrm{m} 2$; excludes protected areas; $5 \mathrm{~km}$ transmission buffer

"Wind resource $>300 \mathrm{~W} / \mathrm{m} 2$; excludes protected areas; $5 \mathrm{~km}$ rosd buffer

"Wind resource > 300W/m2; excludes protected areas; $5 \mathrm{~km}$ road and transmission buffer

Excludes regions with very low wind resource (Northwest, Red River Delta, Southeast)

Figure D-4. Wind resource by region (expressed in square kilometers of land meeting the given set of constraints) 


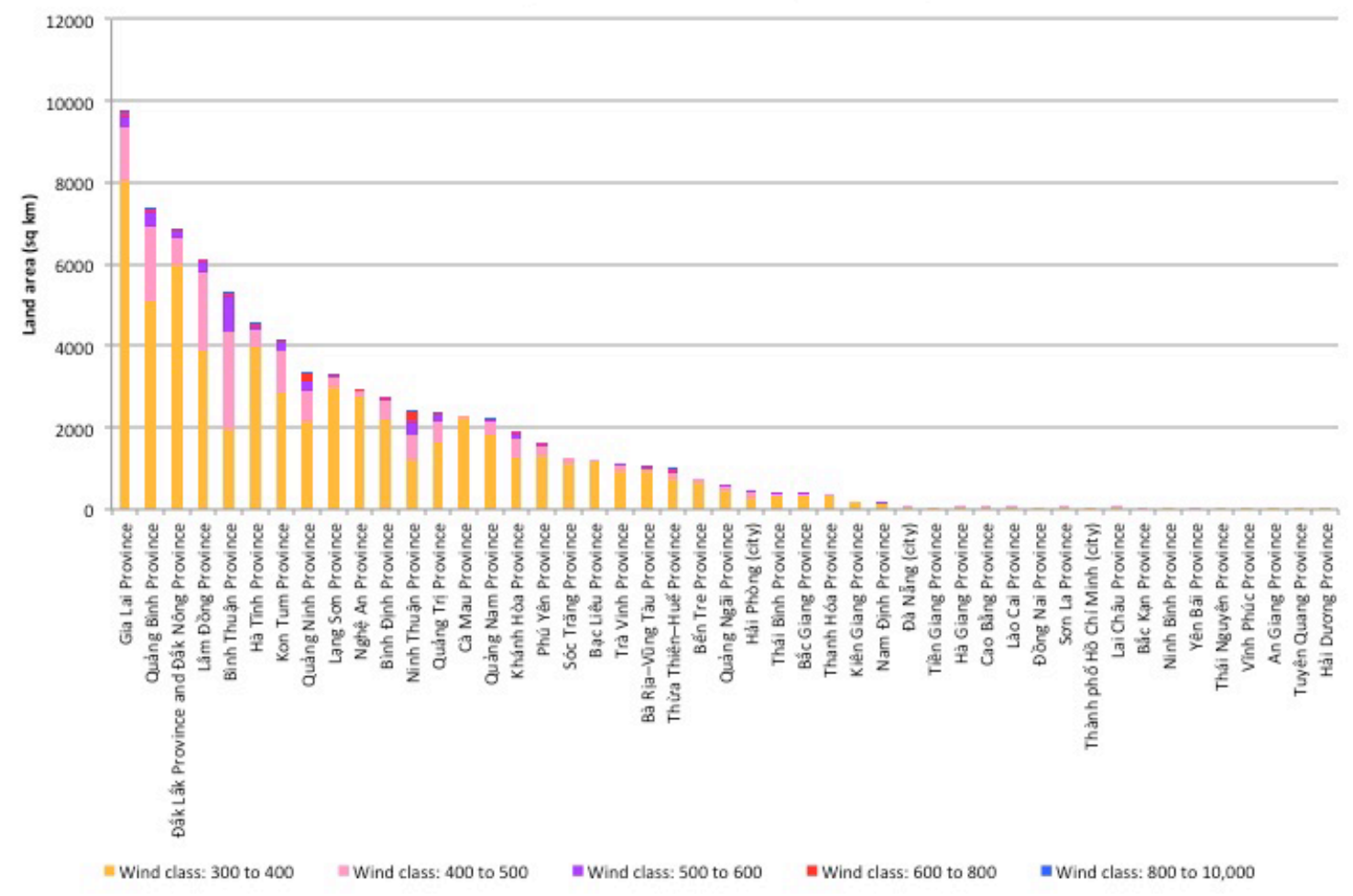

Provinces not listed contain no areas with an annual wind power density greater than or equal to $300 \mathrm{~W} / \mathrm{m}^{2}$

Figure D-5. Land area by province and wind class (no constraints) 